\title{
Numerical investigation on the kinetic characteristics of the Yigong landslide in Tibet, China
}

\author{
Zili Dai ${ }^{1}$, Fawu Wang ${ }^{2}$, Hufeng Yang ${ }^{3}$, Shiwei Qin ${ }^{1}$ \\ ${ }^{1}$ Department of Civil Engineering, Shanghai University, Shanghai, 200444, China \\ $5 \quad{ }^{2}$ Department of Geotechnical Engineering, Tongji University, Shanghai 200092, China \\ ${ }^{3}$ Department of Geological Engineering, Southwest Jiaotong University, Chengdu 610031, China
}

Correspondence to: Zili Dai (zilidai@shu.edu.cn)

\begin{abstract}
To analyse the kinetic characteristics of a rapid landslide that occurred on 9 April 2000 in Tibet, China, a meshfree numerical method named Smoothed Particle Hydrodynamics (SPH) is introduced, and two-dimensional and threedimensional models are established in this work. Based on the numerical simulation, the landslide motion process is reproduced and the kinetic characteristics are analysed combined with the field investigation data. In the kinetic analysis, the landslide velocity, run-out distance, landslide accumulation, and energy features are discussed. Simulation results show that the landslide mass undergoes an acceleration stage after failure, then the kinetic energy dissipates gradually due to the friction and collision during the landslide propagation. Finally, the landslide mass blocks the Yigong river and forms a huge

15 landslide dam and an extensive barrier lake. The peak velocity is calculated to be about $100 \mathrm{~m} / \mathrm{s}$, and the run-out distance is approximately $8,500 \mathrm{~m}$. The simulation results basically match the data measured in field, thus verifying the good performance of the presented SPH model. This approach can provide a new way to predict hazardous areas and estimate the hazard intensity of rapid landslides.
\end{abstract}

\section{Introduction}

20 Rapid landslides are a kind of catastrophic geological hazard which can cause very serious economic and human losses (Dai et al., 2019b). According to Huang (2007), about 80\% large-scale rapid landslides in China occurred in the Tibetan Plateau. Among which, over 50 large-scale landslides were distributed along the Sichuan-Tibet Highway (Shang et al., 2003a). Therefore, rapid landslides pose a serious threat to the human engineering activities in Tibet, China.

Study on the kinetic characteristics of rapid landslides can contribute to the prediction of the impact area of the rapid landslides and has recently attracted extensive attention of scholars around the world (Wei et al., 2019). Field survey combined with remote sensing technology is the most direct approach to obtain the basic dynamic characteristics and the impact area of rapid landslides. For example, Shang et al. (2003b) described the feathers of geological hazards along the Sichuan-Tibet Highway through field investigations. Fan et al. (2017) analysed the failure mechanism of the Diexi landslide occurred in Sichuan, China based on field investigations and satellite images. Karantanellis et al. (2020) proposed a 
methodology based on the Unmanned Aerial Vehicle (UAV) to study two landslide cases within the territory of Greece. However, field investigation requires much manpower and financial resources, though it can directly obtain the first-hand information of the landslides.

A series of empirical-statistical models have been proposed to predict the run-out distances of landslides as a simplified analytical method. For example, Hunter and Fell (2003) presented a method to predict the post-failure behaviour for rapid landslides in predominantly soil slopes. Huang and Cheng (2017) proposed a simplified model to predict the run-out of slope failures in landfills. Qiu et al. (2018) developed an empirical relationship to predict the travel distances of loess landslides in China. Su et al. (2019) presented an empirical model to predict landslide distance based on energy dissipation and mass point kinematics. The prediction results of the above models fit the measured data well. However, empirical model usually required some hypothetical conditions and it cannot consider the 3D complex terrain of a landslide and energy dissipation during its propagation.

Physical model tests are an effective approach to investigate the failure mechanism and post-failure behaviour of landslides. For example, Zhou et al. (2020) carried out a large-scale physical model test to study the displacement characteristic of landslides. Pu et al. (2020) designed a shaking table test to investigate the dynamic response of loess slopes under the rainfall and earthquake coupling effect. Xie et al. (2020) performed series of model tests to investigate the sliding behaviour of rotational landslides. Normally these model tests were in small-scale, and size effect is the main limitation. Tang et al. (2020) designed a large-scale centrifuge test model to investigate the deformation characteristics of reservoir landslides. However, these tests are very expensive and time-consuming.

With a rapid development of computer technology, a various of numerical methods have been developed and widely applied in all fields. Numerical simulation is becoming an important approach for landslide research, especially its stability analysis,

50 failure mechanisms and motion processes. For instance, mesh-based methods, such as the finite difference method (FDM) and the finite element method (FEM) have been widely applied in slope stability analysis (Ding et al., 2012; Chen et al., 2019), failure mechanism analysis (Maihemuti et al., 2016; Xiong et al., 2018), and failure process simulation (Bernander et al., 2016; Tang et al., 2017). Recently, mesh-free methods have been rapidly developed and widely applied due to their unique capability and advantages to handle the problems with large deformation and free surface. For example,

55 Discontinuous Deformation Analysis (DDA) and Discrete Element Method (DEM) have been widely applied to simulate the motion process of flow-like landslides (Liu et al., 2020; Peng et al., 2020; Zhu et al., 2020). Besides, Particle Flow Code (PFC) has been often used for the runout behaviour simulation of catastrophic landslides (Wei et al., 2019; Wang et al., 2020). Smoothed Particle Hydrodynamics (SPH) is a mesh-free method which has been proved to be applicable for kinetic characteristics analysis of flow-like landslides (Pastors et al., 2015; Cuomo et al., 2016; Yu et al., 2018; Zhang et al., 2020).

60 In this work, the SPH method is applied to simulate the motion process of the Yigong landslide in both 2D and 3D. The kinetic characteristics during the propagation are analysed, including the sliding path, movement velocity, runout distance, 
accumulation, and energy features. The simulation results are compared with the survey data in field, which shows that the SPH model can accurately analyse the kinetic characteristics of rapid landslides.

\section{Geological setting and landslide features}

\section{$65 \quad 2.1$ Geological setting}

On 9 April 2000, the Yigong landslide occurred at Zhamunong gully in Bomi County, southeastern Tibet, China. The

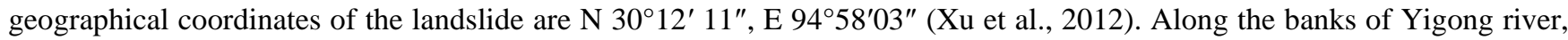
the mountains are very high and steep, which are covered with thick snow over 4,000 $\mathrm{m}$ and with dense vegetation below $3,500 \mathrm{~m}$. The valleys in this area are very deep under the erosions of glaciers and rivers.

70 The rock masses in the study area are main granitoid rocks, which have experienced strong weathering and have been partially metamorphosed into slate and granitic gneiss (Shang et al., 2003b; Zhou et al., 2016). The surface of the slope is composed of quaternary loose colluvial deposits. Thick glaciers and snow covered the slope rock, which could decrease the shear strength of the geomaterial after melting and increase the weight of the sliding mass. Due to the collision between the Eurasian Plate and Indian Plate, active faults are well-developed in the Tibetan Plateau. Jiali Fault and Yigong-Lulang Fault,

75 two of the major active strike-slip faults (Lee et al., 2003), meet at the mouth of Zhamunong gully, as shown in Figure 1. Earthquakes frequently occurred in the study area. For example, 14 moderate earthquakes $(\mathrm{Ms}=4.0-5.9)$ were recorded around the Yigong lake from 1980 to 1996. Therefore, the tectonic activities in this area caused the rock structure fractured, loosened, and weakened, which provided favourable conditions for the Yigong landslide occurrence.

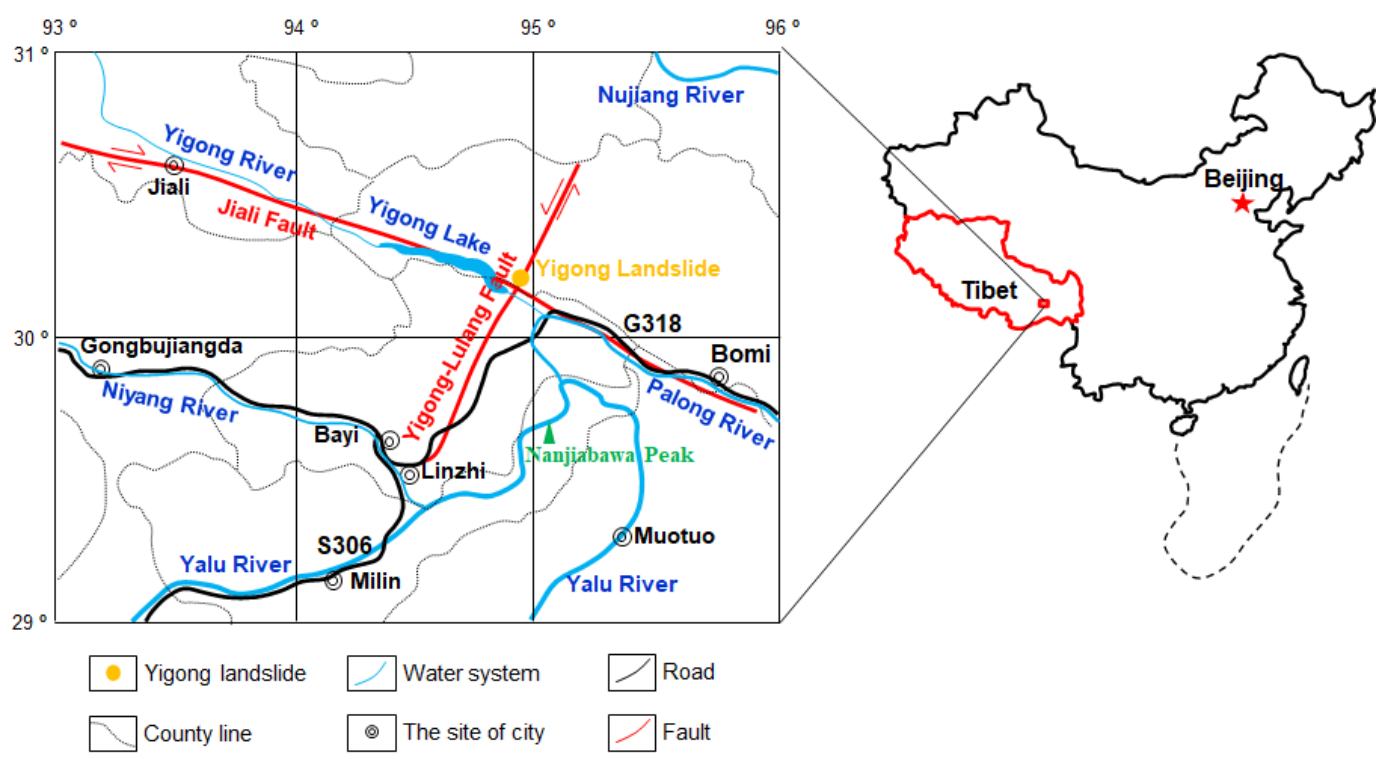

80 Figure 1: Location of the Yigong landslide. 
The study area belongs to the temperate sub-humid plateau monsoon climate area. Influenced by the warm-wet air currents from the Indian Ocean, the weather is humid with clear four seasons and abundant in rainfall and sunshine. According to the local meteorological station, the annual rainfall averages $876.9 \mathrm{~mm}$, and the cumulative sunshine hours is 1,544 hours. It was reported that the antecedent precipitation from 1 April to 9 April, 2000 was $42.9 \mathrm{~mm}$, which was a main trigger of the landslide. Figure 2 is the average temperature in the study area during March and April in 2000. It shows that the average temperature gradually increased in that period, which might result in the glacier melting in the source area, thus may have increased the pore water pressure in the geomaterials and decreased the shear strength.

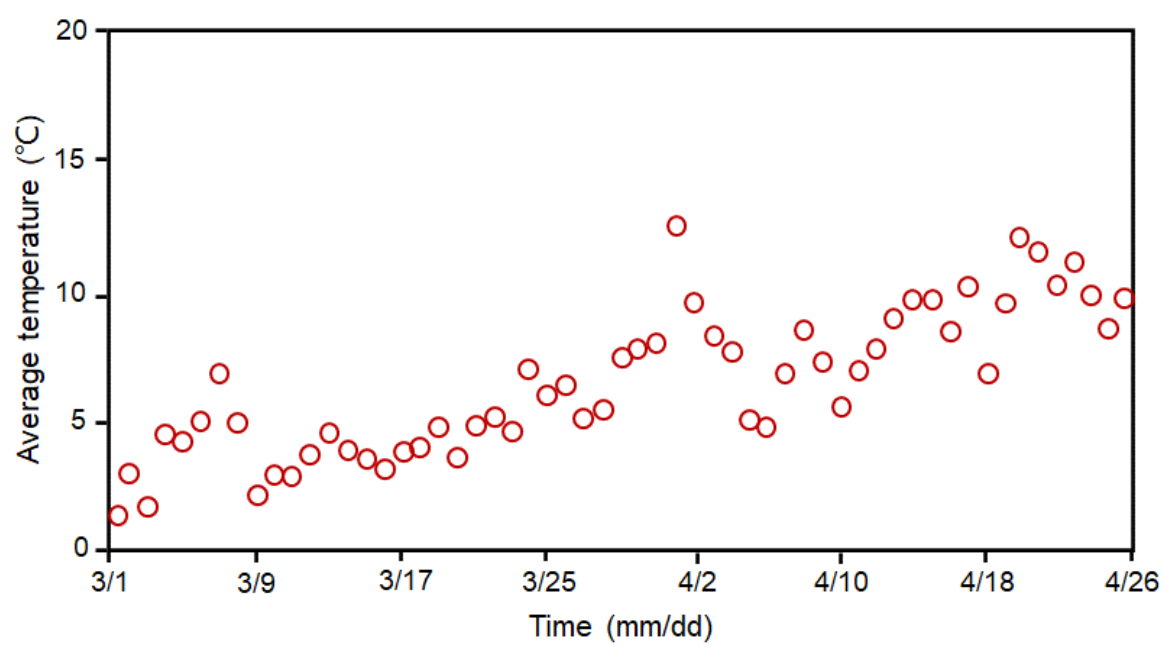

Figure 2: Average temperature in the study area during 1 March to 30 April in 2000.

90

Figure 3 shows an aerial view of the Yigong landslide occurred in Zhamunong gully (the base map is taken from Google Earth). About $3.0 \times 10^{8} \mathrm{~m}^{3}$ rock and soil slid down along the gully for about $3 \mathrm{~min}$, the sliding direction is around $225^{\circ}$. The horizontal run-out distance is about $8,000 \mathrm{~m}$, and the vertical dropdown is about 3,330 $\mathrm{m}$ from its source area at 5,520 $\mathrm{m}$ to its sediment fan at $2,190 \mathrm{~m}$. The maximum sliding velocity of the landslide mass is higher than $100 \mathrm{~m} / \mathrm{s}$, and the average velocity is about $40 \mathrm{~m} / \mathrm{s}$.

Figure 4 is the topographic contour map of the Yigong landslide. The red dash line shows the landslide boundary, and the total surface area of this landslide was about $12.9 \mathrm{~km} 2$. The elevation of the landslide top is about 5,360 m, and the lowest elevation of the deposit area is about 2,200 m. Figure 5 shows the topographic map of the Yigong landslide in 3D. The slope at the both sides of the Zhamunong gully are very steep. Figure 6 shows the path profile of this landslide. The blue dashed line represents the estimated original slope surface before the landslide, and the green solid line is the present slope surface measured after the occurrence of the landslide. As shown in Figure 6, the landslide could be identified by three major zones: source zone, transfer zone and deposit zone. The characteristics of the three zones are described as below. 
https://doi.org/10.5194/nhess-2020-289

Preprint. Discussion started: 27 October 2020

(C) Author(s) 2020. CC BY 4.0 License.

\section{(c) (i)}

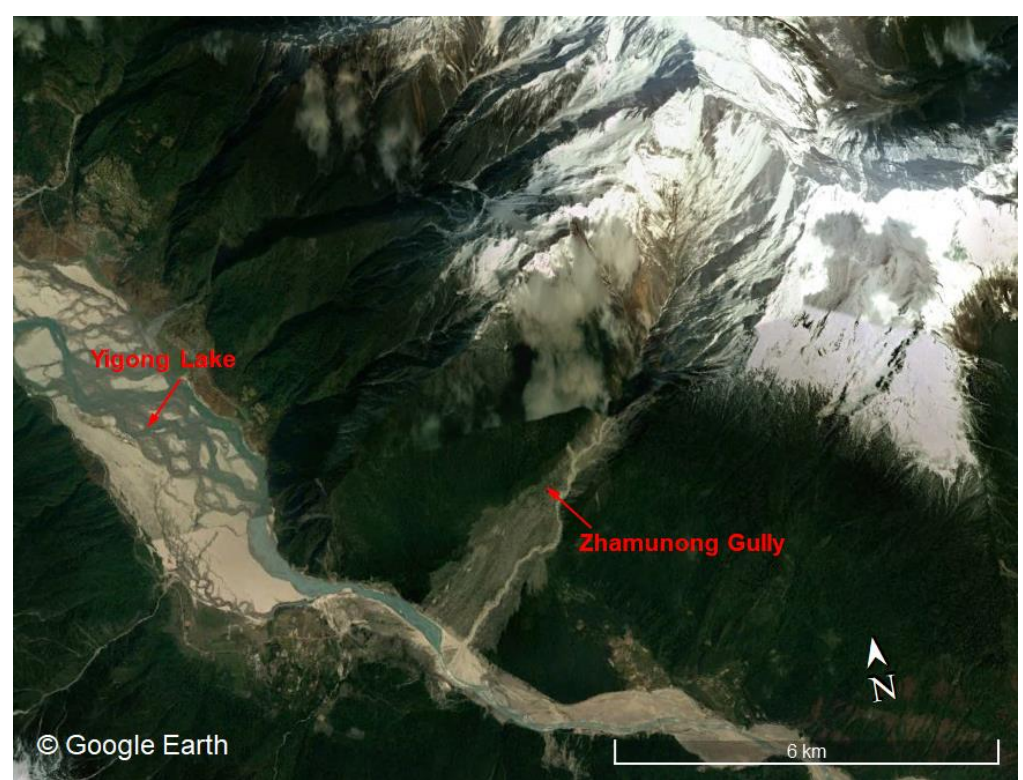

Figure 3: Oblique view of the landslide $\odot$ Google Earth.

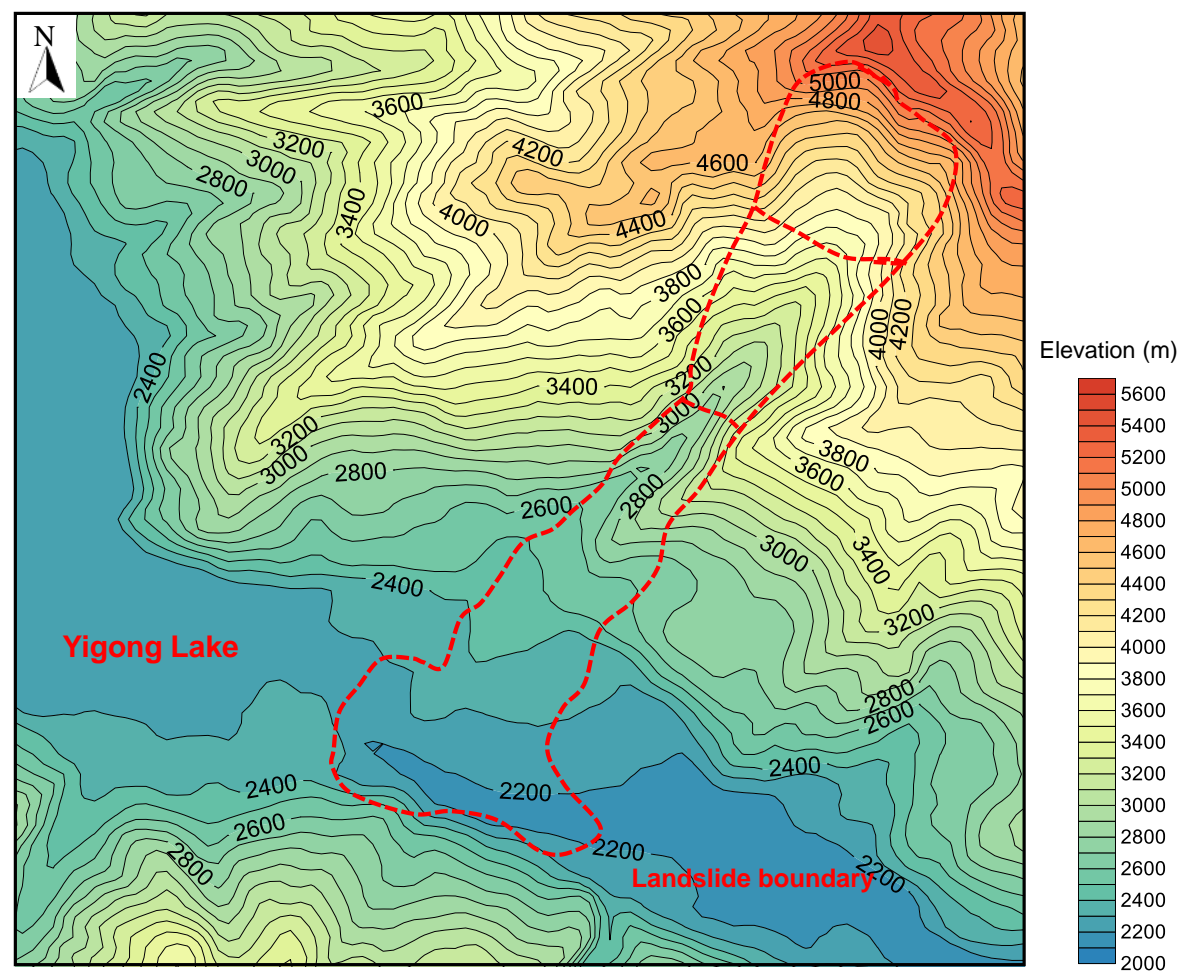

Figure 4: Topographic contour map of the Yigong landslide.

\section{Natural Hazards and Earth System Sciences \\ Discussions


https://doi.org/10.5194/nhess-2020-289

Preprint. Discussion started: 27 October 2020

(C) Author(s) 2020. CC BY 4.0 License.

(c) (i)
Natural Hazards

and Earth System

Sciences

Discussions

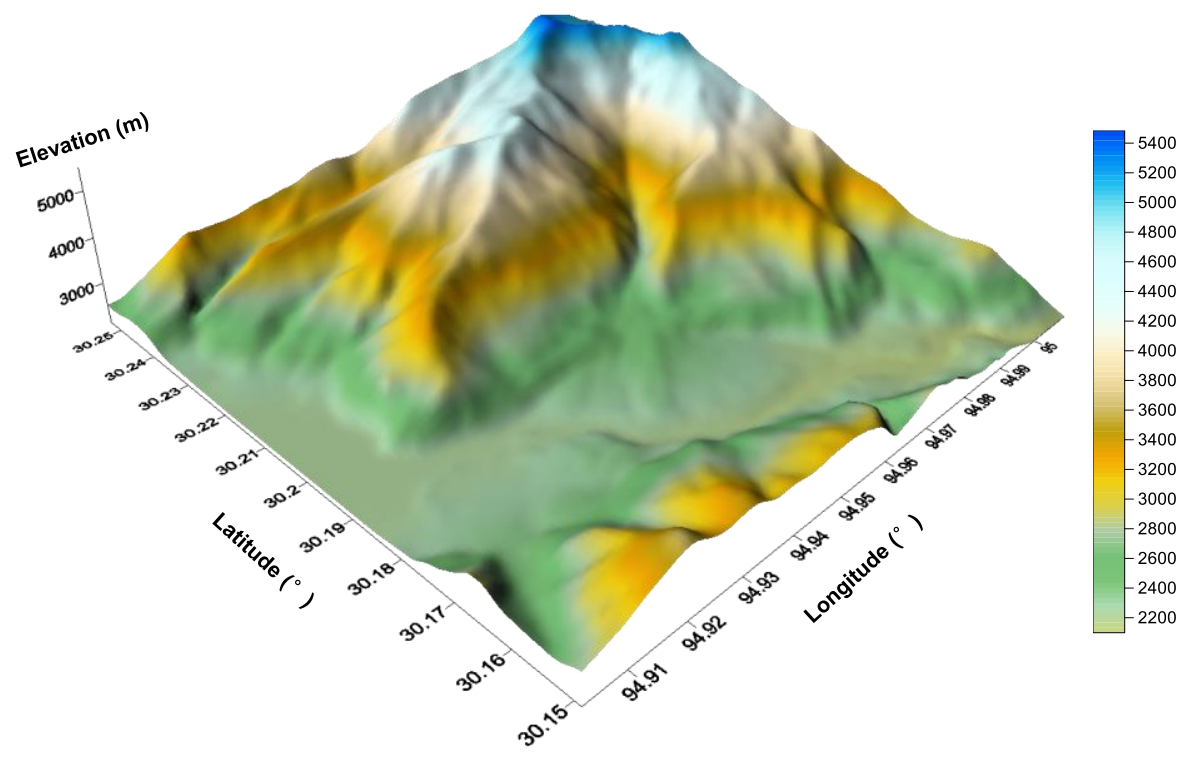

Figure 5: Three-dimensional topographic map of the Yigong landslide.

110

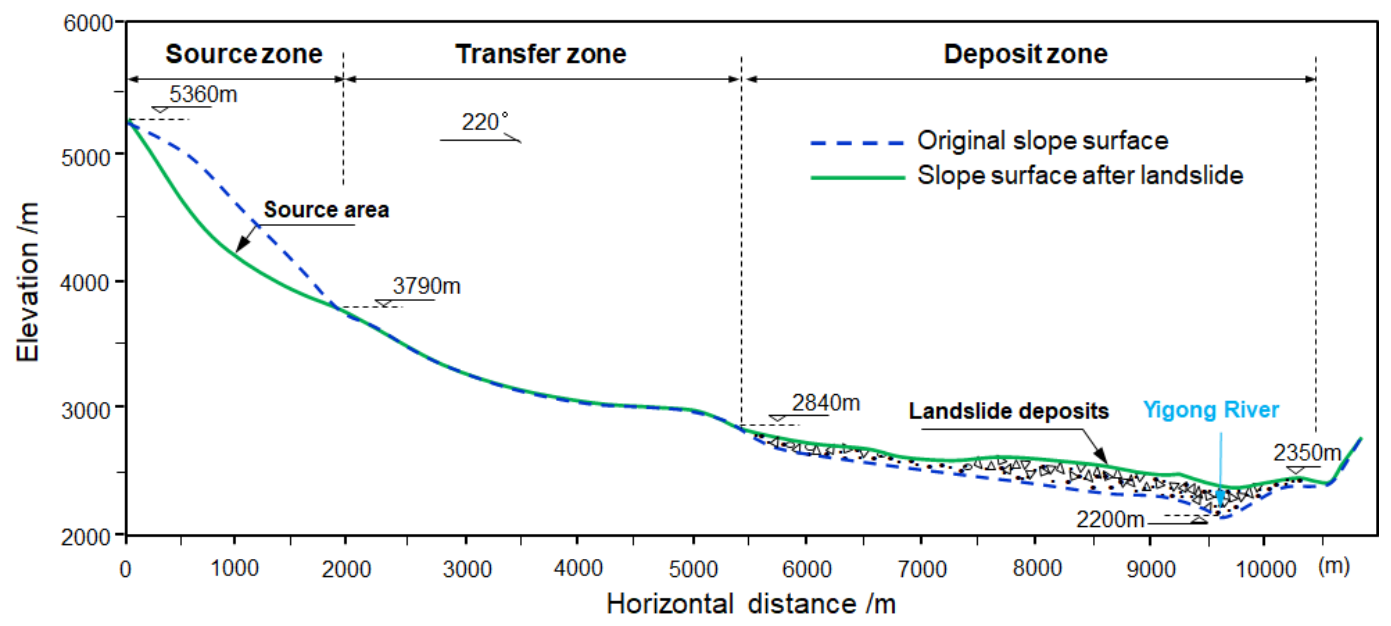

Figure 6: Path profile of the Yigong landslide (Based on Yin, 2000).

\subsubsection{Source zone}

Figure 7 shows an oblique view of the source zone of the Yigong landslide, which is located at the top of the Zhamunong

115 gully. It covered an area of about $1.40 \mathrm{~km}^{2}$. The elevation of the source area sharply decreased from $5,360 \mathrm{~m}$ to $3,750 \mathrm{~m}$, with the slope angle of $40.0^{\circ}$. This area was covered by thick glaciers almost all the year round. The landslide mass was wedge-shaped, wide at the top and narrow at the bottom. It poured down along the creek bed at a high speed. 
https://doi.org/10.5194/nhess-2020-289

Preprint. Discussion started: 27 October 2020

(c) Author(s) 2020. CC BY 4.0 License.

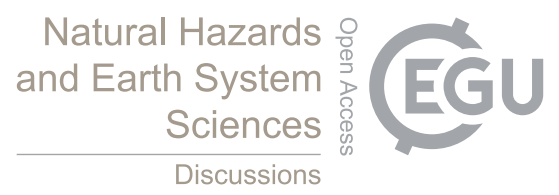

\subsubsection{Transfer zone}

The transfer zone of this landslide covered an area of about $3.46 \mathrm{~km}^{2}$. The axial length of this zone is about $3,200 \mathrm{~m}$, and the

120 width ranges from $780 \mathrm{~m}$ to $1,500 \mathrm{~m}$. The elevation of this zone ranges from $3,790 \mathrm{~m}$ to $2,840 \mathrm{~m}$, with the height difference of $950 \mathrm{~m}$. The average slope of this zone is about $16.0^{\circ}$, which was much gentler than that of the source zone. As shown in Figure 8, a lot of boulders were distributed in the gully. Most of them were angular with a diameter over $0.5 \mathrm{~m}$.

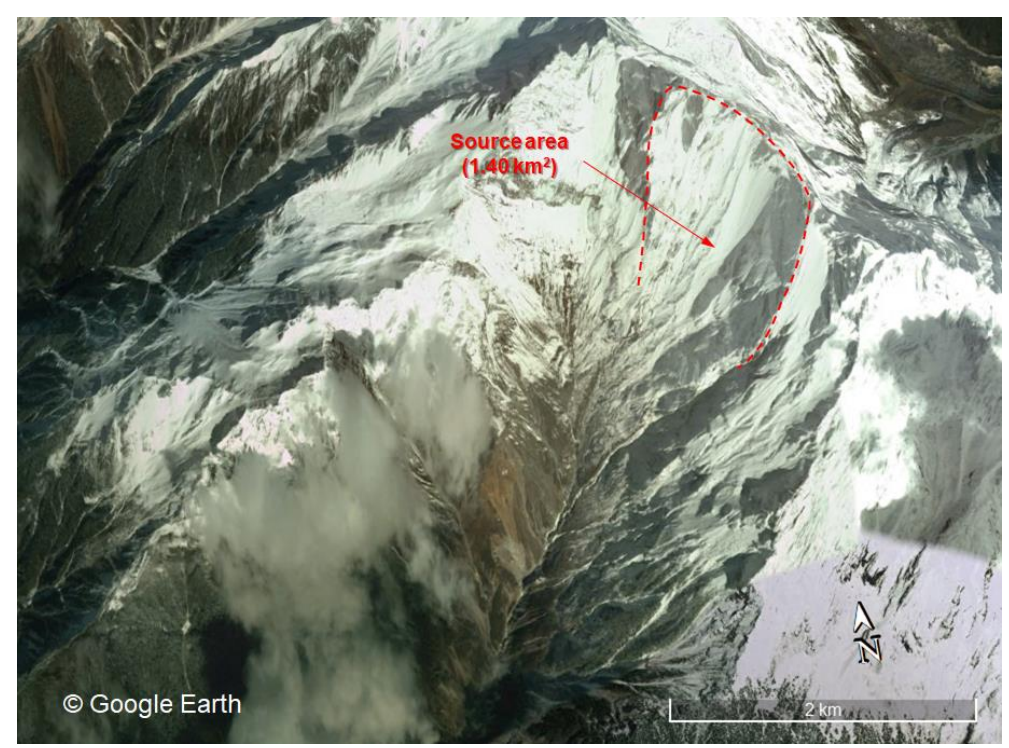

Figure 7: Oblique view of the source area $\odot$ Google Earth.

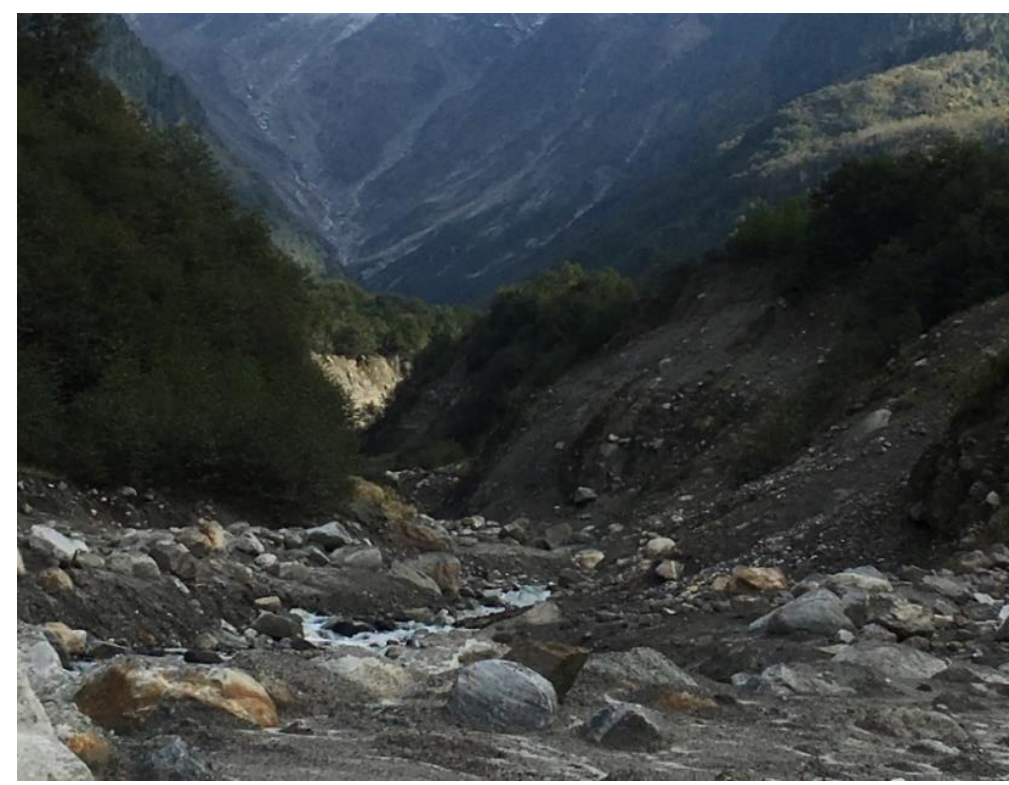

Figure 8: Boulders in the transfer zone. 
https://doi.org/10.5194/nhess-2020-289

Preprint. Discussion started: 27 October 2020

(C) Author(s) 2020. CC BY 4.0 License.

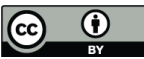

\section{Natural Hazards and Earth System Sciences \\ Discussions}

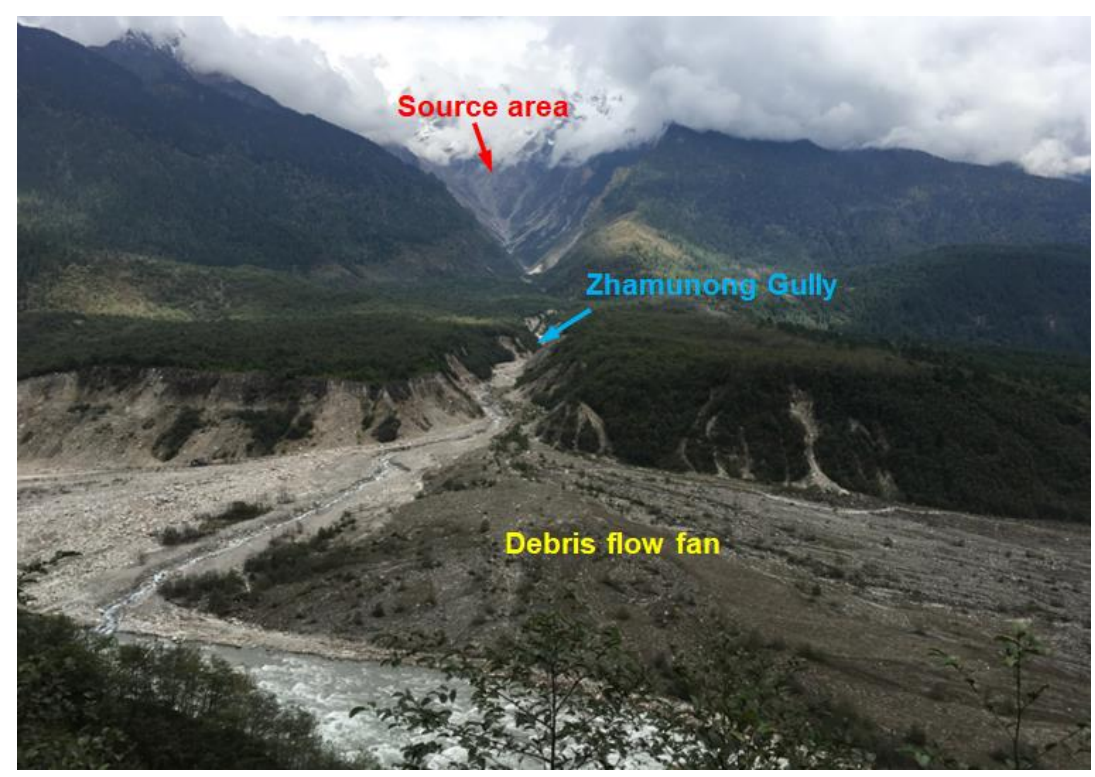

Figure 9: Front view of the deposit zone (view direction NE).

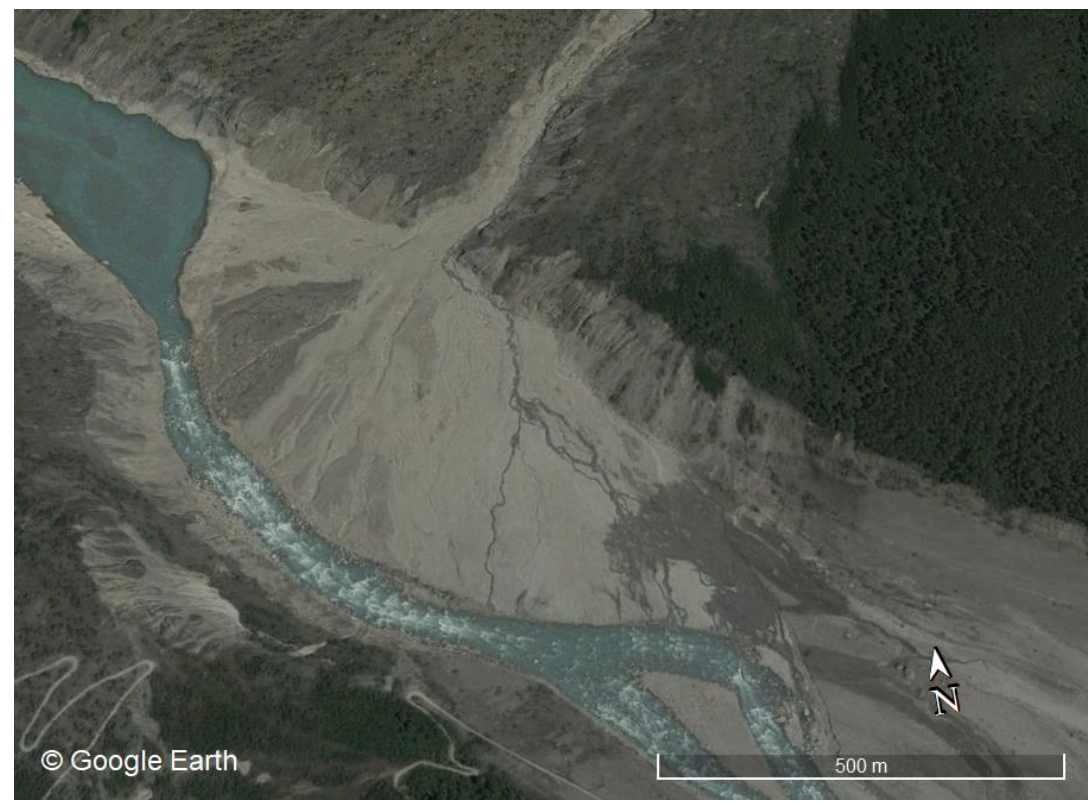

130 Figure 10: Aerial view of the debris fan formed in the Yigong river channel @ Google Earth.

\subsubsection{Deposit zone}

Figure 9 is the front view of the deposit zone of the Yigong landslide. The elevation of this zone ranges from 2,200 $\mathrm{m}$ to $2,800 \mathrm{~m}$, and the average slope is about $6.0^{\circ}$. The area of the landslide accumulation is over $6.0 \times 10^{6} \mathrm{~m}^{2}$, and the average depth of sediment is about $50 \mathrm{~m}$ (Shang et al., 2003a). Due to the high motion velocity, the landslide mass flushed into the 
135 Yigong river and formed a huge landslide dam and an extensive dammed lake. The length of the trumpet-shaped landslide dam is about $4.6 \mathrm{~km}$, the maximum width is $3.0 \mathrm{~km}$, and the dam height is $60-120 \mathrm{~m}$. The dam sloped at $5^{\circ}$ at the upstream side and $8^{\circ}$ at the downstream side (Yin, 2000). After the landslide dam formation, water level of the Yigong lake continuously rose at a rate of about $1 \mathrm{~m} /$ day, which flooded the Yigong tea farm, schools, and villages surrounding the barrier lake. On 10 June 2000, the dam failed and resulted in a devastating flooding, which destroyed farms, villages, bridges,

140 and highways along its route. In recent years, the loose sediment was eroded by water from the Zhamunong gully and formed a debris fan in the Yigong river channel, as shown in Figure 10.

\section{Numerical model}

To investigate the kinetic characteristics of the Yigong landslide, a meshfree numerical method named Smoothed Particle Hydrodynamics (SPH) is applied, and two-dimensional and three-dimensional models are established for the rapid landslide

145 propagation simulation.

\subsection{SPH algorithm}

The SPH method was proposed in 1997 for astrophysical applications (Gingold and Monaghan, 1977). Recently, this method has been widely applied to a large variety of engineering fields (Dai et al., 2017; 2019; Jamalabadi, 2020; Price and Laibe, 2020; Zhu and Zou, 2020). Compared to the mesh-based method, the major advantage of the SPH method is to bypass the

150 need for numerical meshes and avoid the mesh distortion issue and a great deal of computational work to renew the mesh (Ma et al., 2020).

In the SPH method, the subject is represented by a set of particles to which the material properties such as velocity, density, and pressure are associated. The properties are updated for each time step of the simulation following the conservation laws of mass and momentum (Liu and Liu 2003).

155 In this study, the flow-like landslide is assumed as a kind of incompressible viscous fluid. Therefore, the continuity and momentum equations are expressed by:

$$
\begin{aligned}
& \frac{d \rho_{i}}{d t}=\sum_{j=1}^{N_{i}} m_{j}\left(v_{j}-v_{i}\right) \tilde{\nabla}_{i} W_{i j} \\
& \frac{d v_{i}}{d t}=\sum_{j=1}^{N_{i}} m_{j}\left[\frac{p_{i}}{\left(\rho_{i}\right)^{2}}+\frac{p_{j}}{\left(\rho_{j}\right)^{2}}+\delta \Pi_{i j}\right] \tilde{\nabla}_{i} W_{i j}+F_{i}
\end{aligned}
$$

where $\rho$ is the particle density, $t$ is the time, and $m$ is the particle mass. $W$ is a smooth function, $v$ is the velocity and $F$ is the body force. $\delta$ is the Kronecker delta and $\Pi$ is an artificial viscosity, which is used to improve the stability of the numerical results (Monaghan and Gingold, 1983). $p$ is the pressure, which is calculated by an equation of state in this study: 
$p=\frac{\rho_{0} c_{s}^{2}}{\gamma}\left[\left(\frac{\rho}{\rho_{0}}\right)^{\gamma}-1\right]$

where $\rho_{0}$ is the reference density, $c_{s}$ is the numerical speed of sound, and $\gamma$ is the exponent of the equation of state.

\subsection{SPH model of the Yigong landslide}

\subsubsection{Material model}

The landslide mass is a mixture of water, soil, and rock, which is complicated to describe. Hunger (1995) proposed a concept of "equivalent fluid", which is intended to simulate the bulk behavior of the moving mass. Pirulli (2010) used a frictional and a Voellmy rheology model to simulate the motion process of rapid flowlike landslides across three-dimensional terrain. Recently, some viscous fluid models have been widely used in the numerical modelling of flow-like landslides (Zhang and

170 Xiao, 2019). In the presented SPH model, the flow-like landslide mass is assumed as a Bingham fluid, and the relationship between the shear stress and the shear strain rate is defined as:

$\tau=\left(\eta+\frac{p \tan \varphi+c}{\left(D_{\Pi}\right)^{1 / 2}}\right) D$

where $\tau$ is the shear stress of the fluid, $\eta$ is the yield viscosity coefficient in fluid dynamics, $p$ is the pressure which can be obtained by Eq. (3). $c$ and $\varphi$ are the cohesion angle and internal friction of the geomaterial. $D$ and $D_{\Pi}$ are the strain rate and

175 its second invariant.

\subsubsection{Boundary treatment}

SPH method is ideal to deal with the free surface boundary. In the presented model, the free surface is identified through the criterion below:

$\rho^{*}<k \rho_{0}$

180 where $\rho^{*}$ is the calculated density through the Eq. (1) and $\rho_{0}$ is the reference density. $k$ is the free surface parameter. When the particle is identified as a boundary particle, then zero pressure is applied.

For the solid wall boundary, ghost particles are placed on the boundary lines to exert repulsive forces and avoid the particles crossing the boundary. The velocities of the ghost particles are set to be zero to satisfy the non-slip boundary condition. Detail description of the non-slip boundary condition please refer to Dai et al. (2014).

\section{$185 \quad$ 3.2.3 Time integration}

In a Lagrangian framework, the coordinates of each particles are updated at each time steps. A velocity-Verlet scheme is introduced in this SPH model to perform time integration. 
$\boldsymbol{X}_{n+1}=\boldsymbol{X}_{n}+\boldsymbol{V}_{n} \Delta t+\frac{1}{2} \boldsymbol{a}_{n} \Delta t^{2}$

$\boldsymbol{V}_{n+1 / 2}=\boldsymbol{V}_{n}+\frac{1}{2} \boldsymbol{a}_{n} \Delta t$

$\boldsymbol{V}_{n+1}=\boldsymbol{V}_{n+1 / 2}+\frac{1}{2} \boldsymbol{a}_{n+1} \Delta t$

where $\boldsymbol{X}, \boldsymbol{V}$ and $\boldsymbol{a}$ are the displacement, velocity, and acceleration field, respectively.

\section{Kinetic characteristics of the Yigong landslide}

\subsection{Two-dimensional modelling}

According to the landslide profile in Figure 6, a two-dimensional SPH model is established in this study to simulate the post failure behavior of the Yigong landslide, as shown in Figure 11. In this model, there are 13,568 particles in all, including 7,662 blue particles, which represent the landslide mass and 5,906 grey boundary particles, with a diameter of $8 \mathrm{~m}$. The initial velocities of the particles are set to be zero. After slope failure, the landslide mass particles can slide down the slope under the action of gravity, while the boundary particles remain stationary throughout the simulation. The strength characteristics of the Yigong landslide mass were studied through a series of high-speed ring shear tests and rotary shear tests in the previous researches (Hu et al., 2015; Wang et al., 2017). According to the test results, the values of the $\mathrm{c}$ and $\varphi$ of the landslide mass can be approximately set as $10 \mathrm{kPa}$ and $20^{\circ}$, respectively.

According to the simulation results, the motion process of the landslide mass takes about $200 \mathrm{~s}$, which is basically consistent with the witnesses' description. Figure 12 presents the slope configurations at different points in time, which shows the motion process of the landslide mass after slope failure. The particles slide down from the top of the Zhamunong gully, and then move along the steep slope by gravity. Finally, these particles run to an equilibrium state and accumulate in the Yigong river channel. The colour represents the velocity of the particles, which shows that the maximum sliding velocity of the landslide mass is about $100 \mathrm{~m} / \mathrm{s}$. To investigate the kinetic characteristics of the landslide, Figure 13 shows the time history curves of the landslide sliding velocity. The blue, red and green curves represent the velocity evolutions of the rear edge, front edge, and the average value of the landslide mass. The peak velocities are $102.6 \mathrm{~m} / \mathrm{s}$ at the front edge, and $72.4 \mathrm{~m} / \mathrm{s}$ at

210 the rear edge, respectively. The average velocity of the landslide mass during the landslide propagation is approximately $39.8 \mathrm{~m} / \mathrm{s}$. After slope failure, landslide body rapidly slides down and accelerates due to the gravity. In this stage, most of the potential energy of the landslide mass is converted into the kinetic energy. After the peak velocity, the kinetic energy is consumed due to the friction, collision, and the breakage of the sliding mass, and the velocity decreases gradually. The overall performance of the sliding mass is accelerated motion in the period 0-50 s and decelerated motion after $50 \mathrm{~s}$. Figure 
https://doi.org/10.5194/nhess-2020-289

Preprint. Discussion started: 27 October 2020

(c) Author(s) 2020. CC BY 4.0 License.

(c) (i)

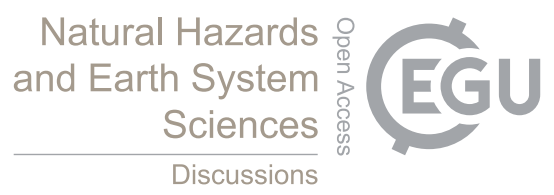

consistent with the measured data. The simulated runout distance is about $8,500 \mathrm{~m}$, which can also match the measured result very well.

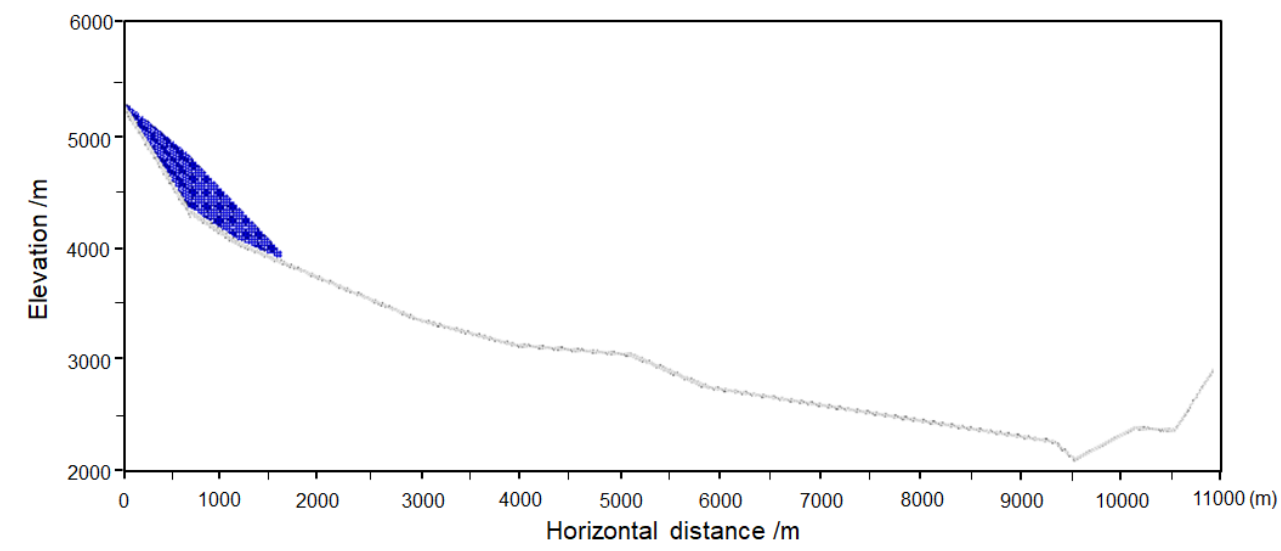

Figure 11: Two-dimensional SPH model for the Yigong landslide.

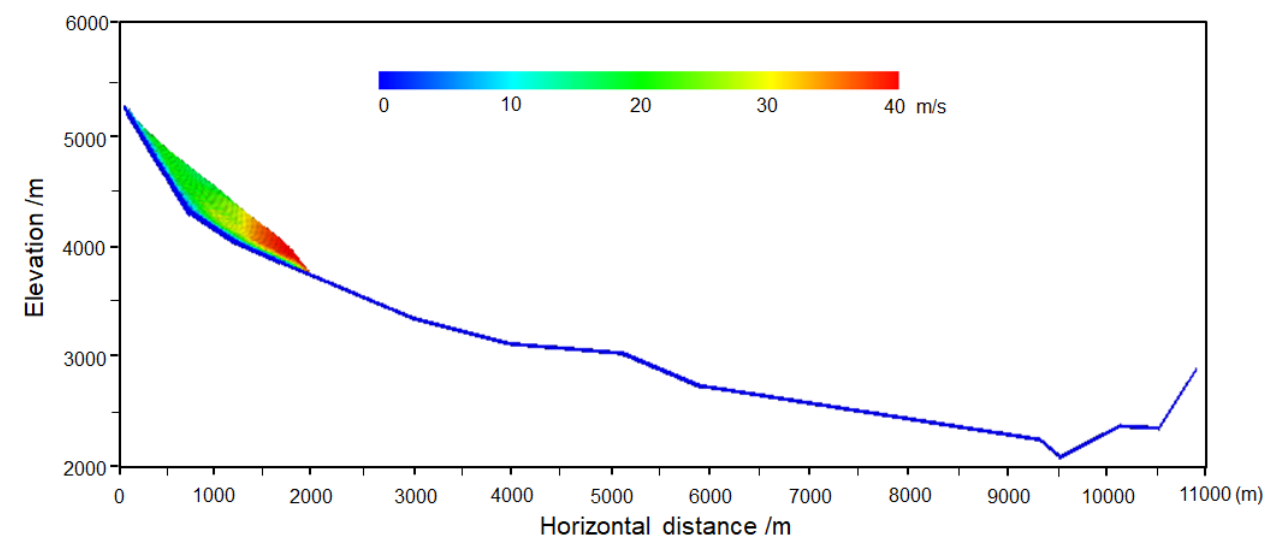

(a) $t=15 \mathrm{~s}$ 
https://doi.org/10.5194/nhess-2020-289

Preprint. Discussion started: 27 October 2020

(c) Author(s) 2020. CC BY 4.0 License.

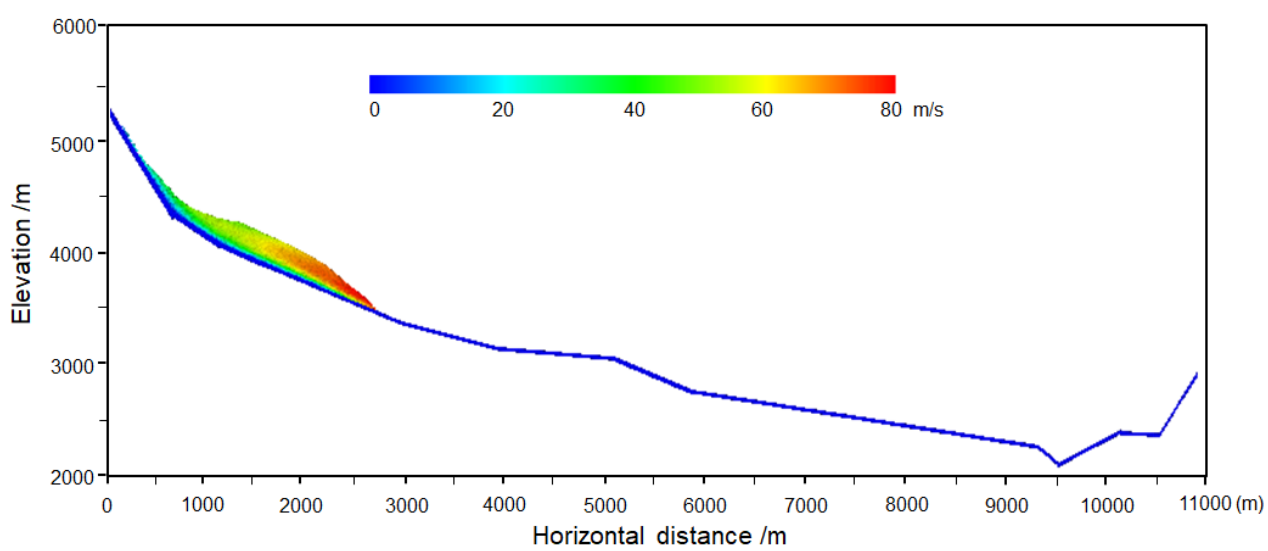

(b) $\mathrm{t}=30 \mathrm{~s}$

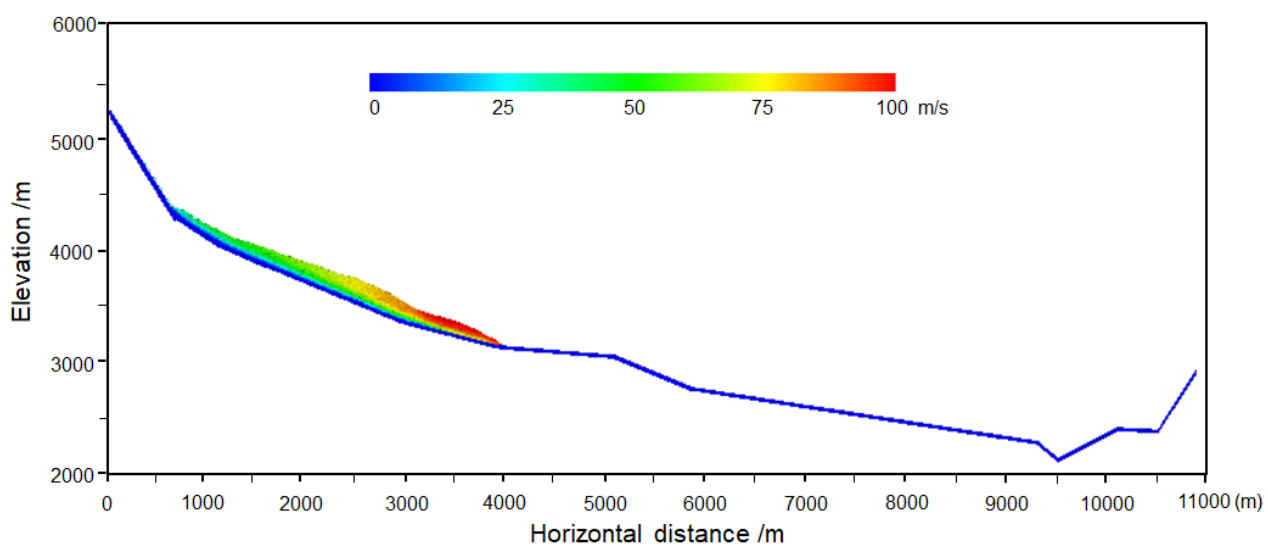

(c) $t=45 \mathrm{~s}$

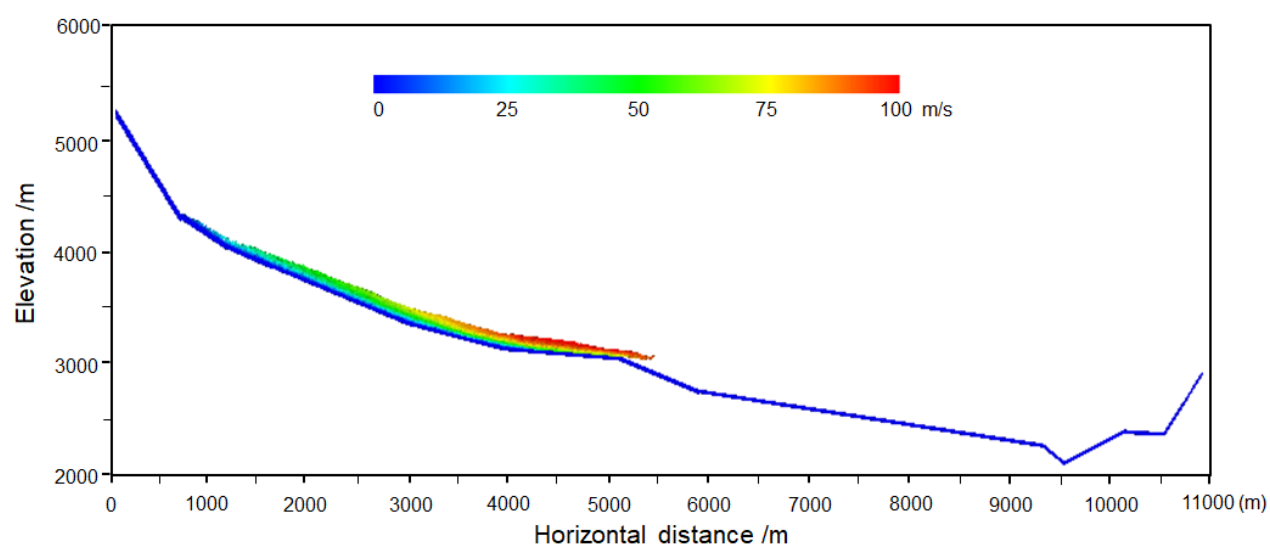

(d) $\mathrm{t}=60 \mathrm{~s}$ 
https://doi.org/10.5194/nhess-2020-289

Preprint. Discussion started: 27 October 2020

(c) Author(s) 2020. CC BY 4.0 License.

(c) (1)
Natural Hazards and Earth System

Sciences

Discussions

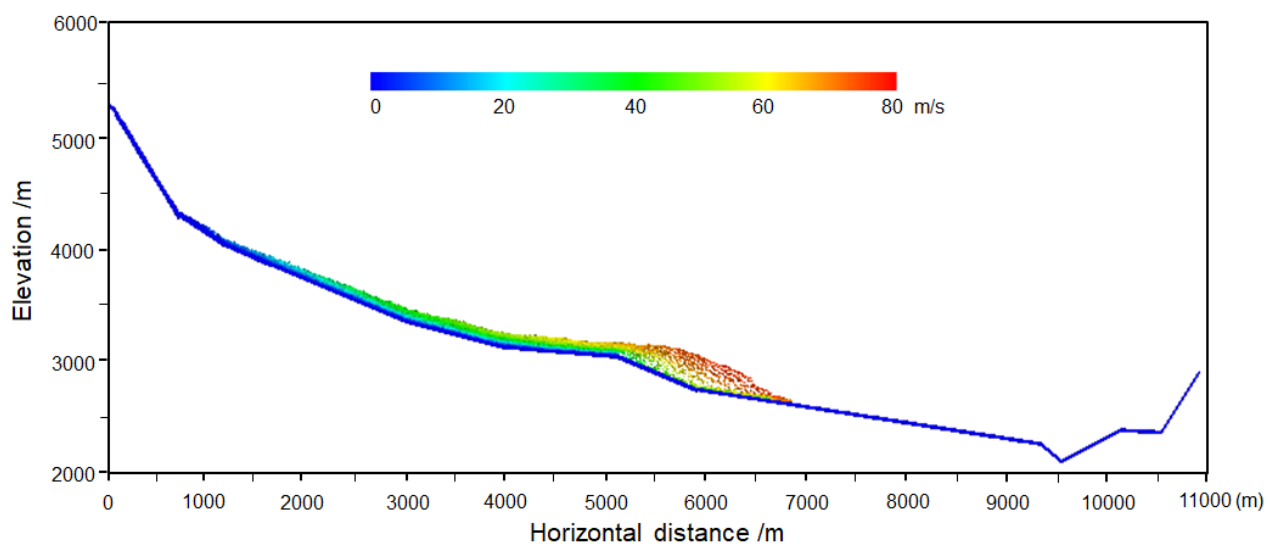

230

(e) $t=80 \mathrm{~s}$

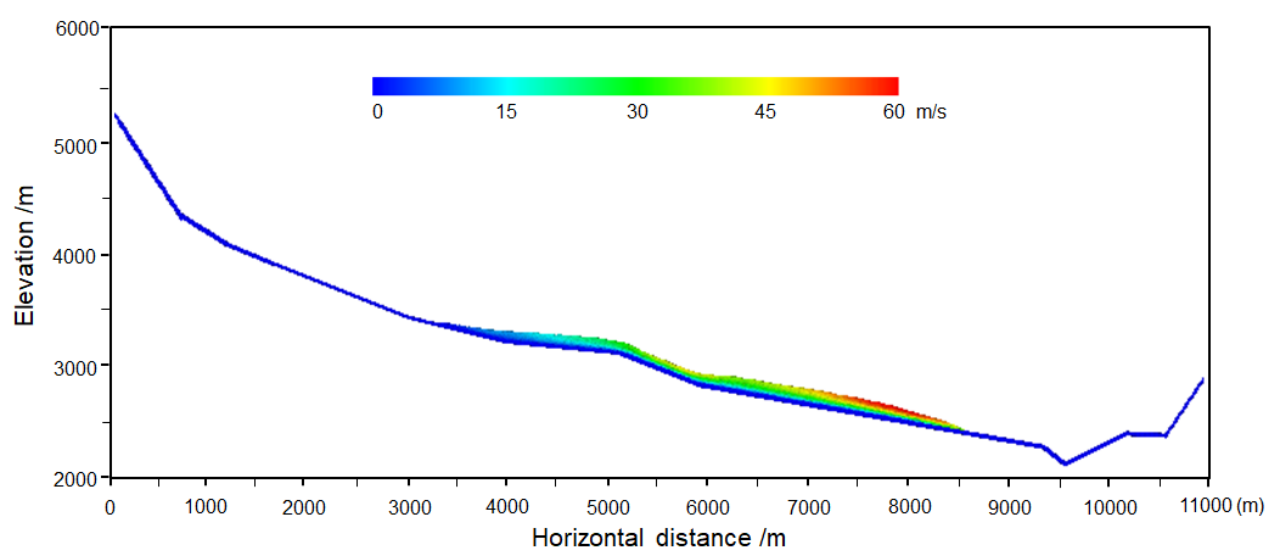

(f) $t=120 \mathrm{~s}$

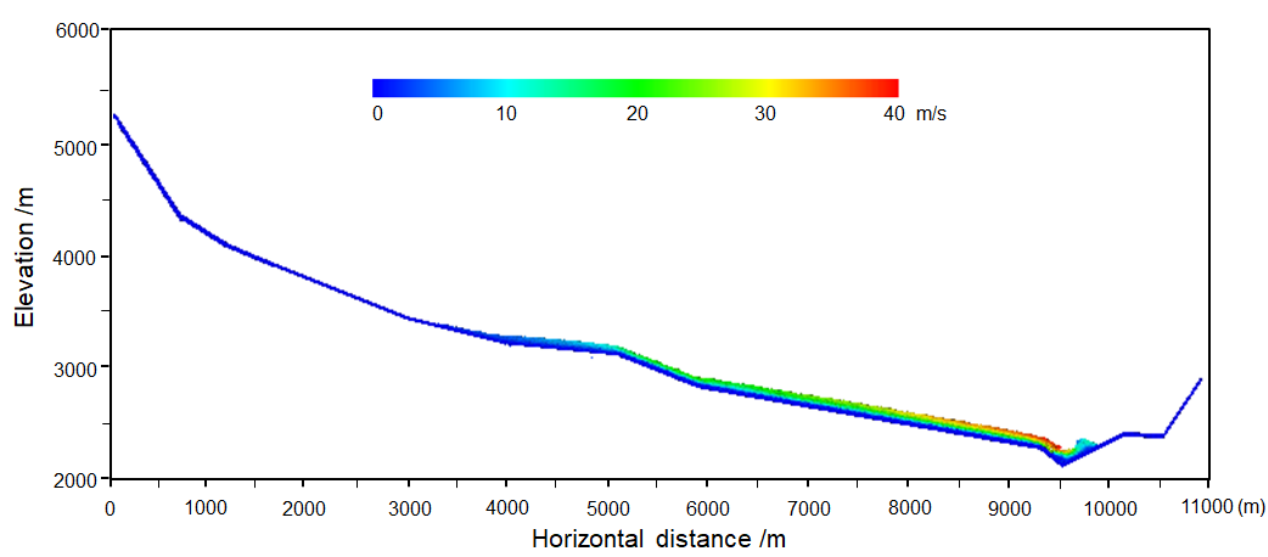

(g) $t=150 \mathrm{~s}$ 
https://doi.org/10.5194/nhess-2020-289

Preprint. Discussion started: 27 October 2020

(c) Author(s) 2020. CC BY 4.0 License.

(c) (1)

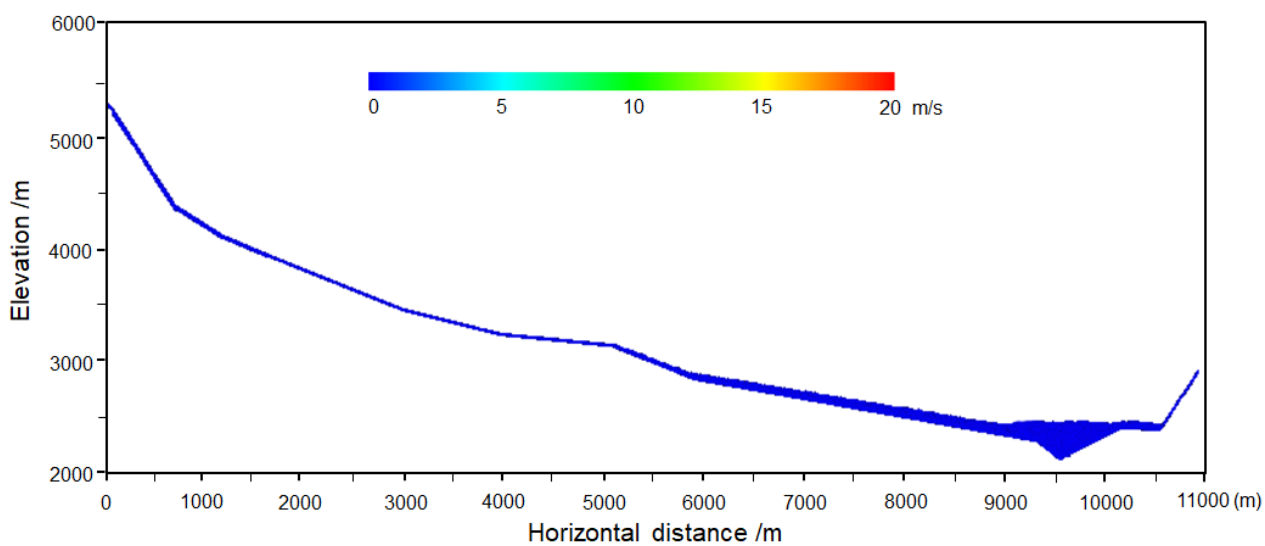

(h) $\mathrm{t}=200 \mathrm{~s}$

Figure 12: Two-dimensional simulated results for the motion process of the Yigong landslide.

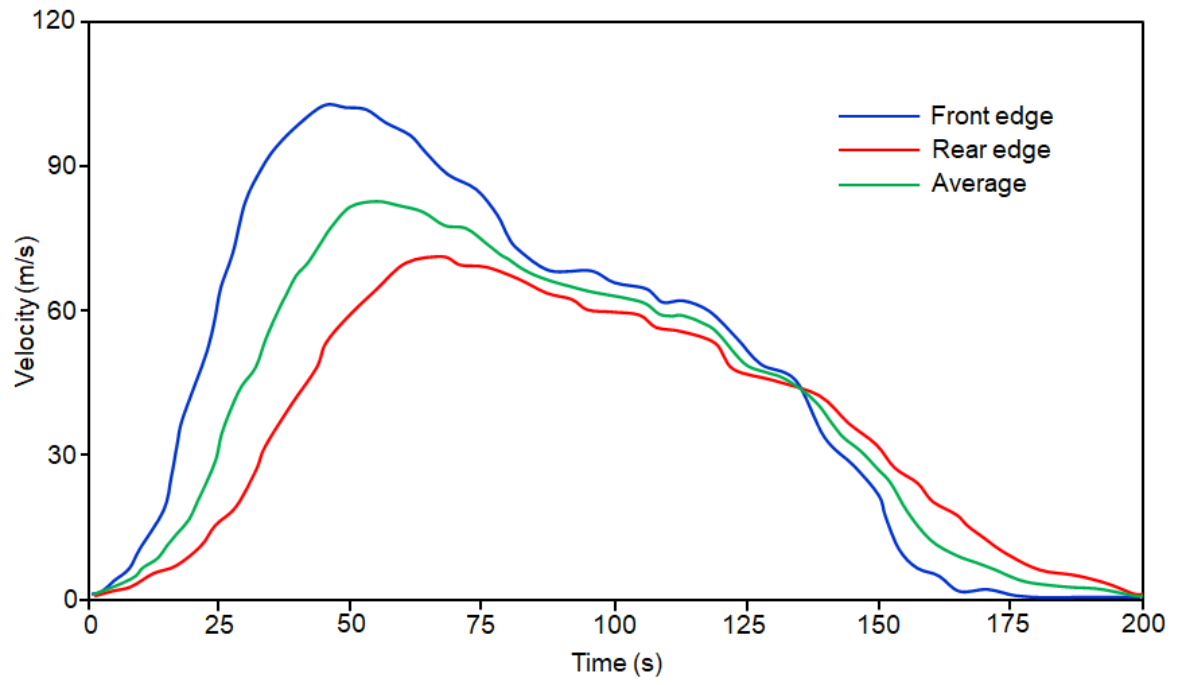

Figure 13: Velocity time history curves of different parts of the landslide body. 


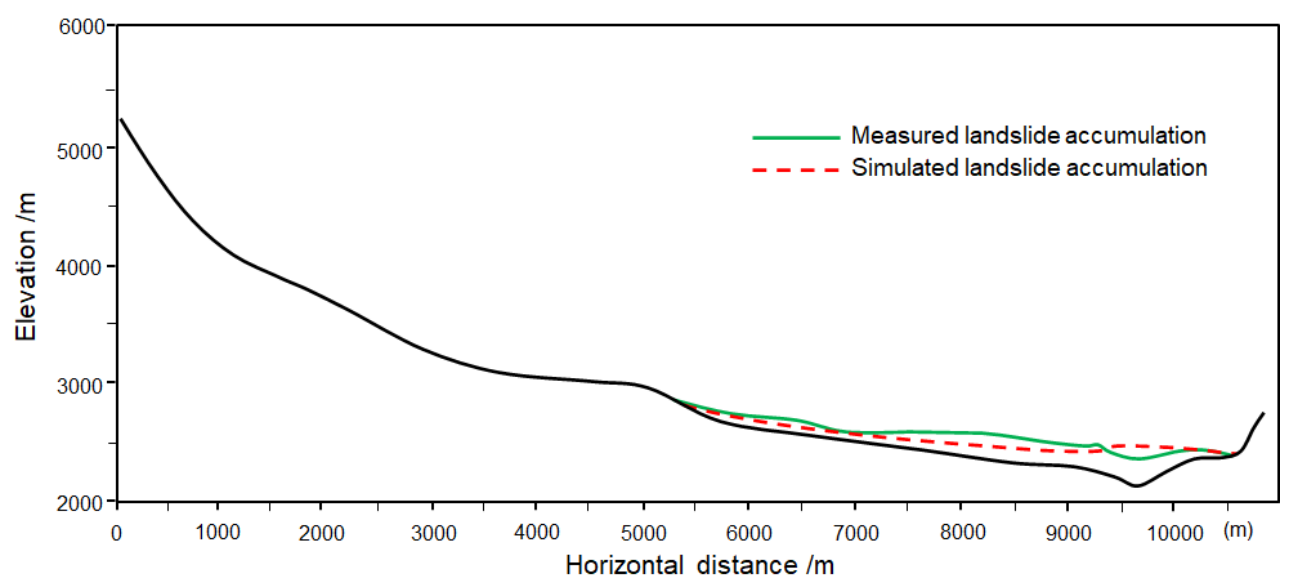

Figure 14: Comparison of simulated and measured landslide accumulation.

\subsection{Three-dimensional modelling}

245 To simulate the landslide propagation across 3D complex terrain, the 2D SPH model is developed into a 3D version. Based on the 3D topographic map shown in Figure 5, a 3D SPH model for the Yigong landslide is established. In this model, the landslide mass in the source area is discretized into about 11,000 particles with a diameter of $20 \mathrm{~m}$. The number of particles along the vertical direction varies in different position according to the depth of the sliding surface in this position. The strength parameters used in 3D simulation are the same as those used in 2D model. Based on this model, the numerical modeling of the Yigong landslide motion across 3D terrain is conducted and the results is shown in Figure 15. The color of the particles in the figures represents the sliding velocity. After slope failure, the landslide mass goes through an acceleration process since the slope is quite steep in the source area. The maximum sliding velocity is about $98.4 \mathrm{~m} / \mathrm{s}$ which appears at $47.5 \mathrm{~s}$ after the slope failure. Afterwards, the landslide mass slows down gradually due to the friction and the collision during the propagation. Finally, the landslide mass crashes into a mountain on the opposite bank of Yigong river and then blocks the

255 river channel. The whole motion process takes about $200 \mathrm{~s}$, and the final depositions of the landslide mass on the runout path are shown in Figure 15(g). The simulated maximum thickness of the landslide deposition is about $120 \mathrm{~m}$, which is consistent with the field measurement result. Figure 16 shows the Yigong landslide accumulation. The shape of the simulated deposition zone is basically in agreement with the observed one. 
https://doi.org/10.5194/nhess-2020-289

Preprint. Discussion started: 27 October 2020

(c) Author(s) 2020. CC BY 4.0 License.

(c) (i)
Natural Hazards 웅 and Earth System Sciences

Discussions

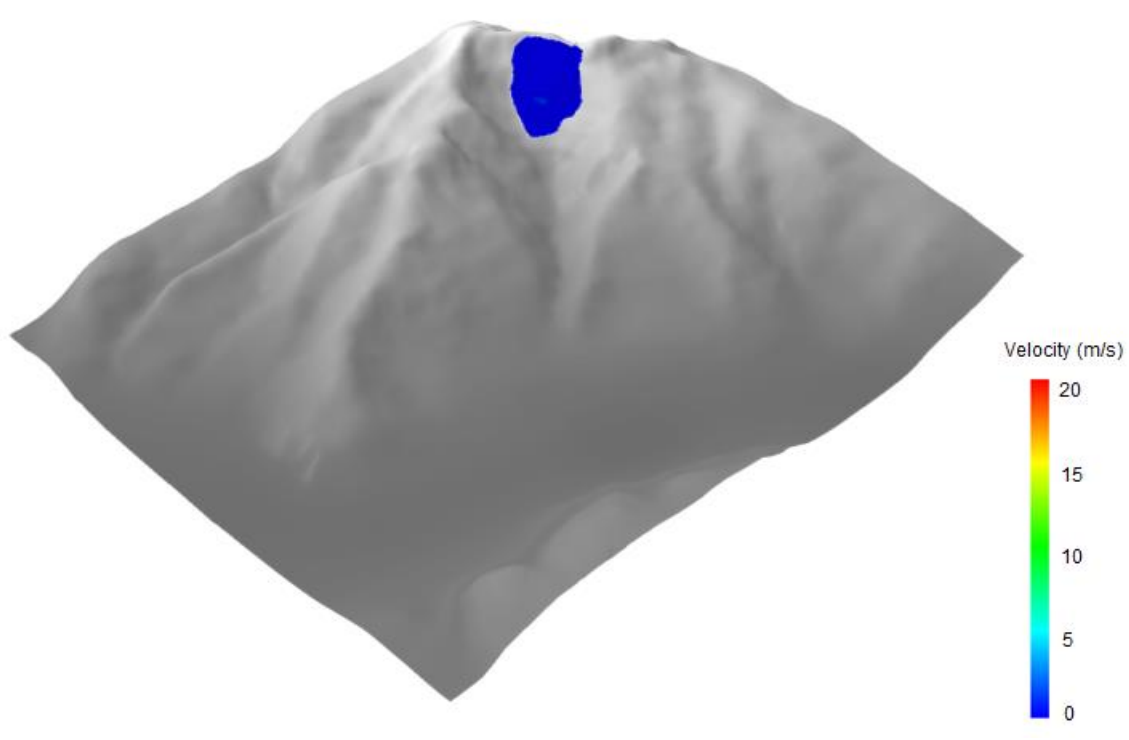

(a) $t=0 \mathrm{~s}$

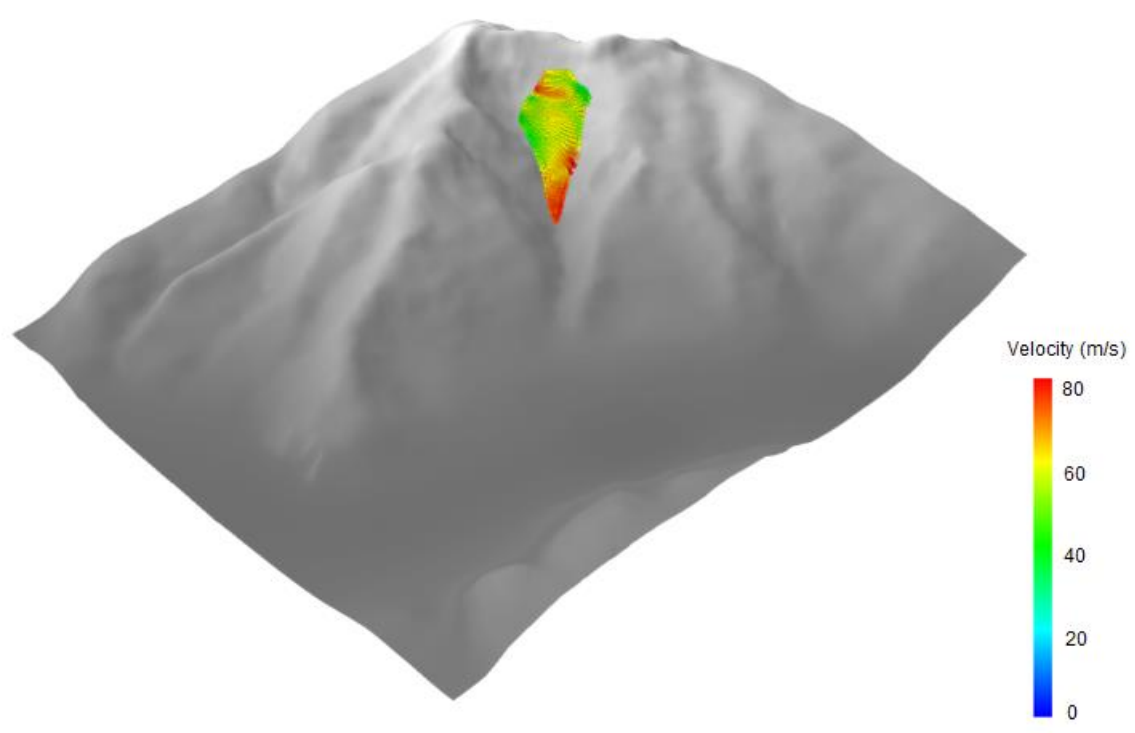

(b) $\mathrm{t}=30 \mathrm{~s}$ 
https://doi.org/10.5194/nhess-2020-289

Preprint. Discussion started: 27 October 2020

(c) Author(s) 2020. CC BY 4.0 License.

(c) (i)
Natural Hazards
and Earth System
Sciences
Discussions

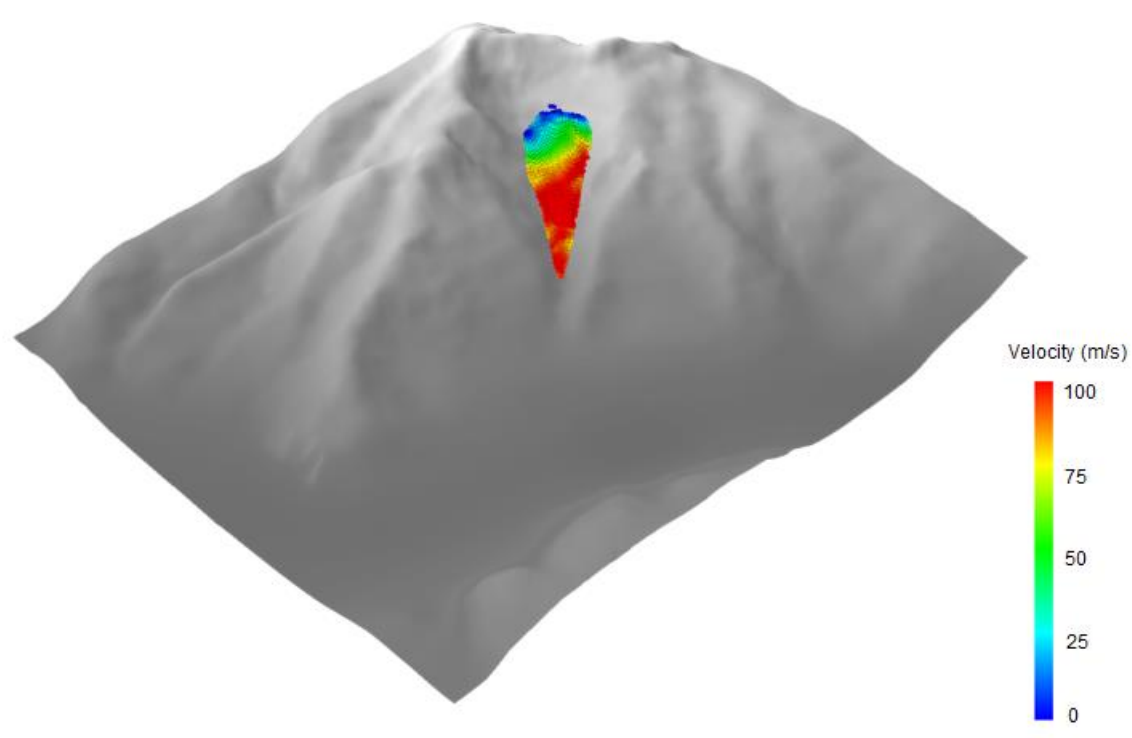

(c) $\mathrm{t}=60 \mathrm{~s}$

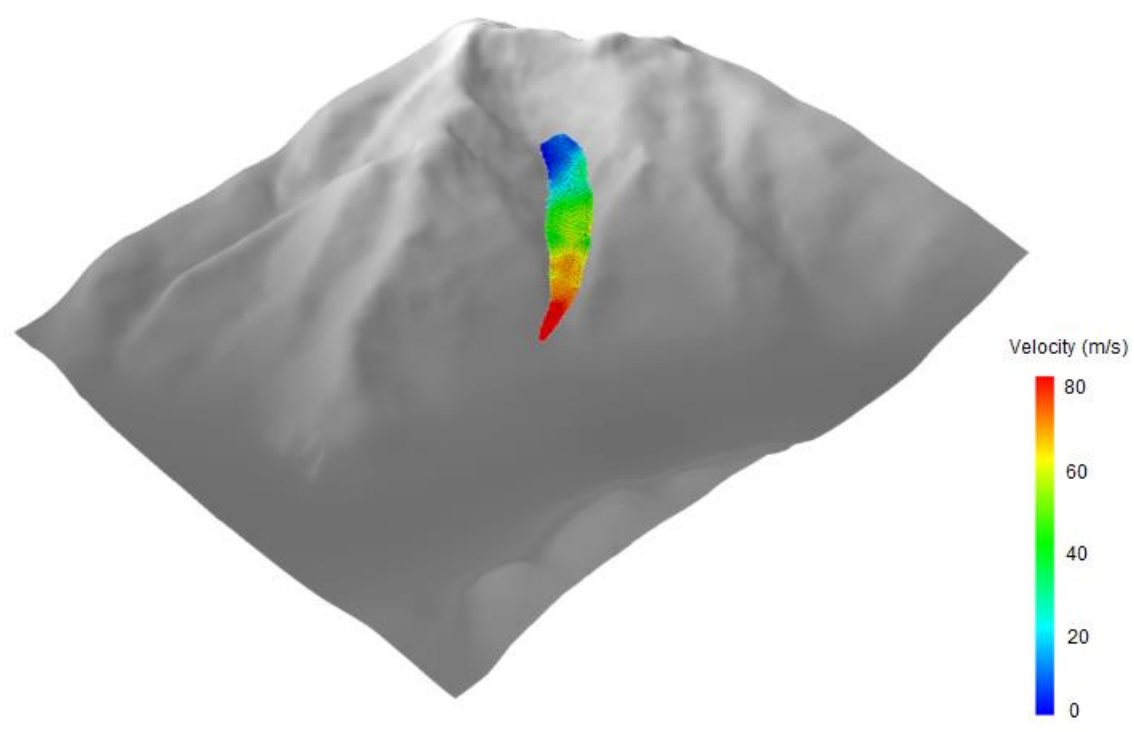

(d) $t=90 \mathrm{~s}$ 
https://doi.org/10.5194/nhess-2020-289

Preprint. Discussion started: 27 October 2020

(c) Author(s) 2020. CC BY 4.0 License.

(c) (i)
Natural Hazards 웅 and Earth System Sciences

Discussions

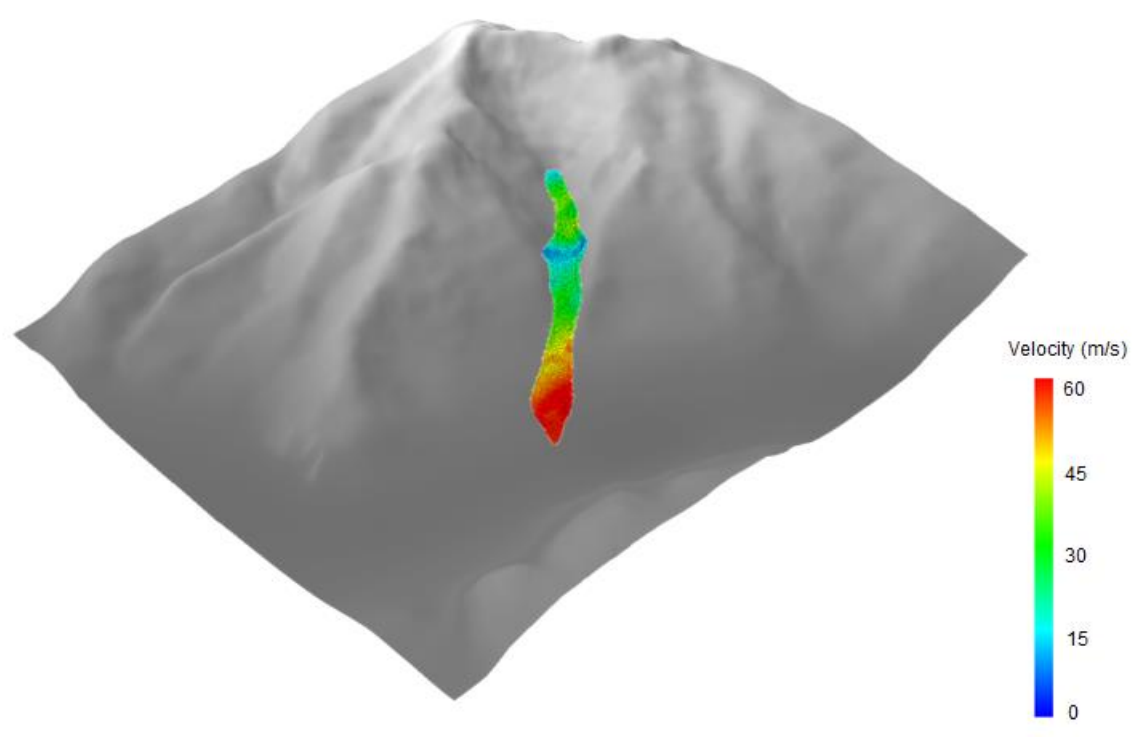

(e) $t=120 \mathrm{~s}$

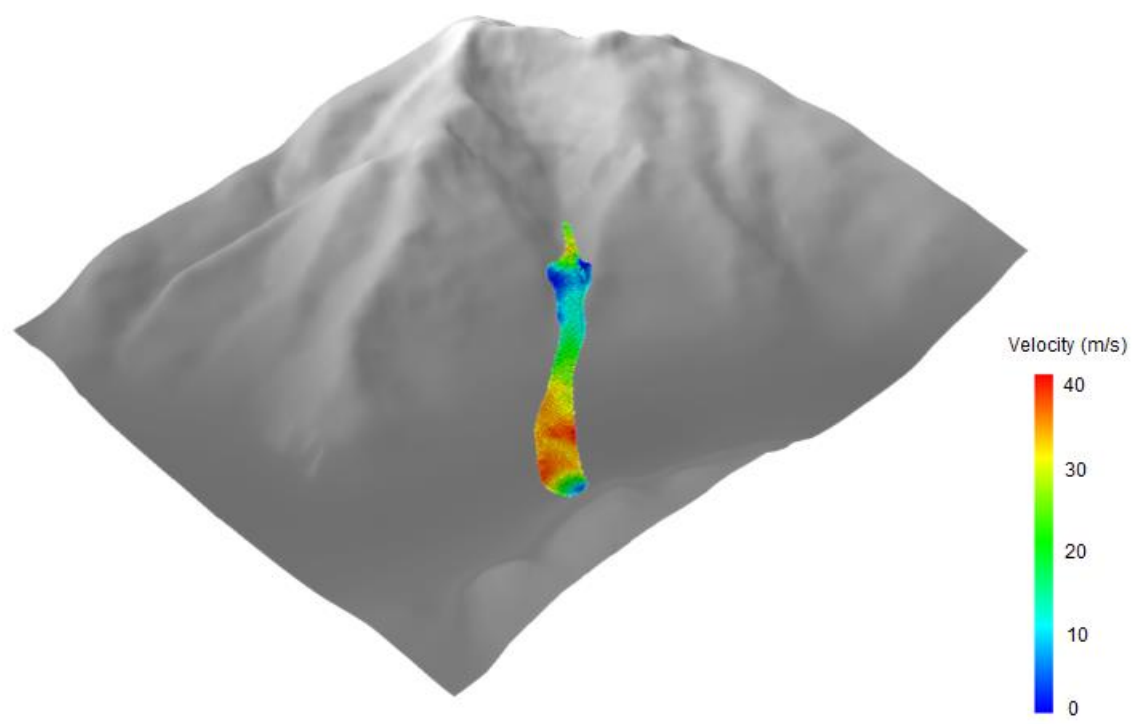

(f) $t=160 s$ 
https://doi.org/10.5194/nhess-2020-289

Preprint. Discussion started: 27 October 2020

(c) Author(s) 2020. CC BY 4.0 License.

(c) (†)
Natural Hazards and Earth System Sciences

Discussions

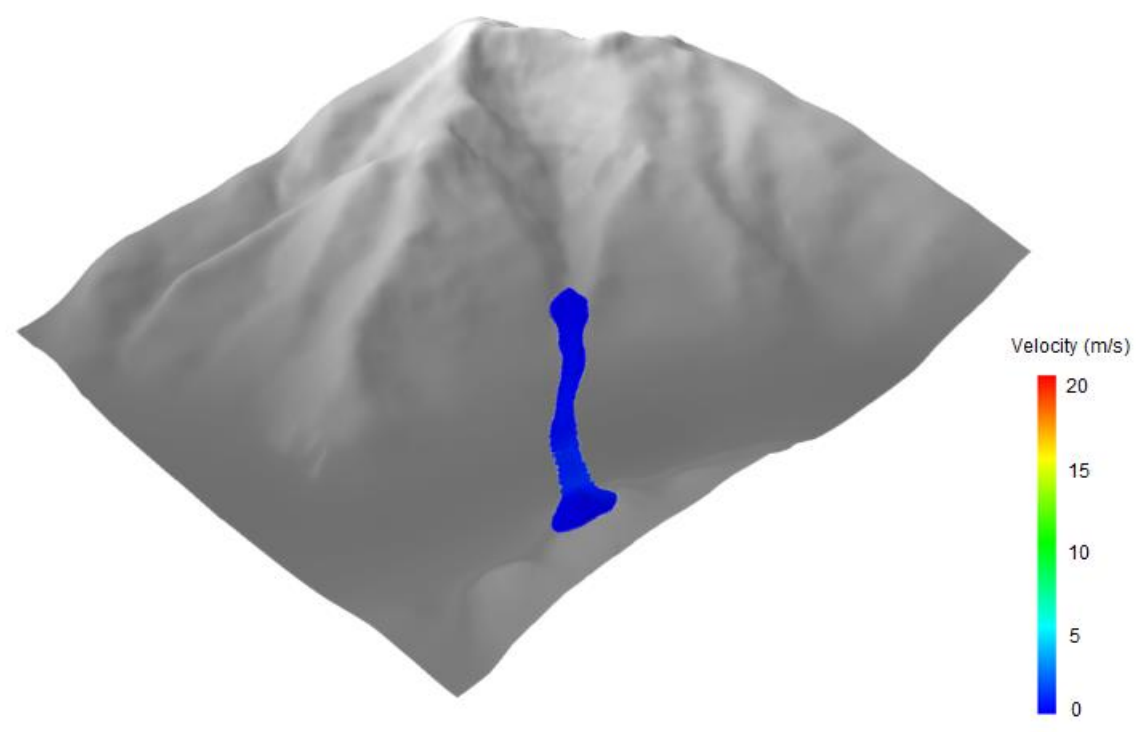

(g) $\mathrm{t}=200 \mathrm{~s}$

Figure 15: Velocity variations in the Yigong landslide.

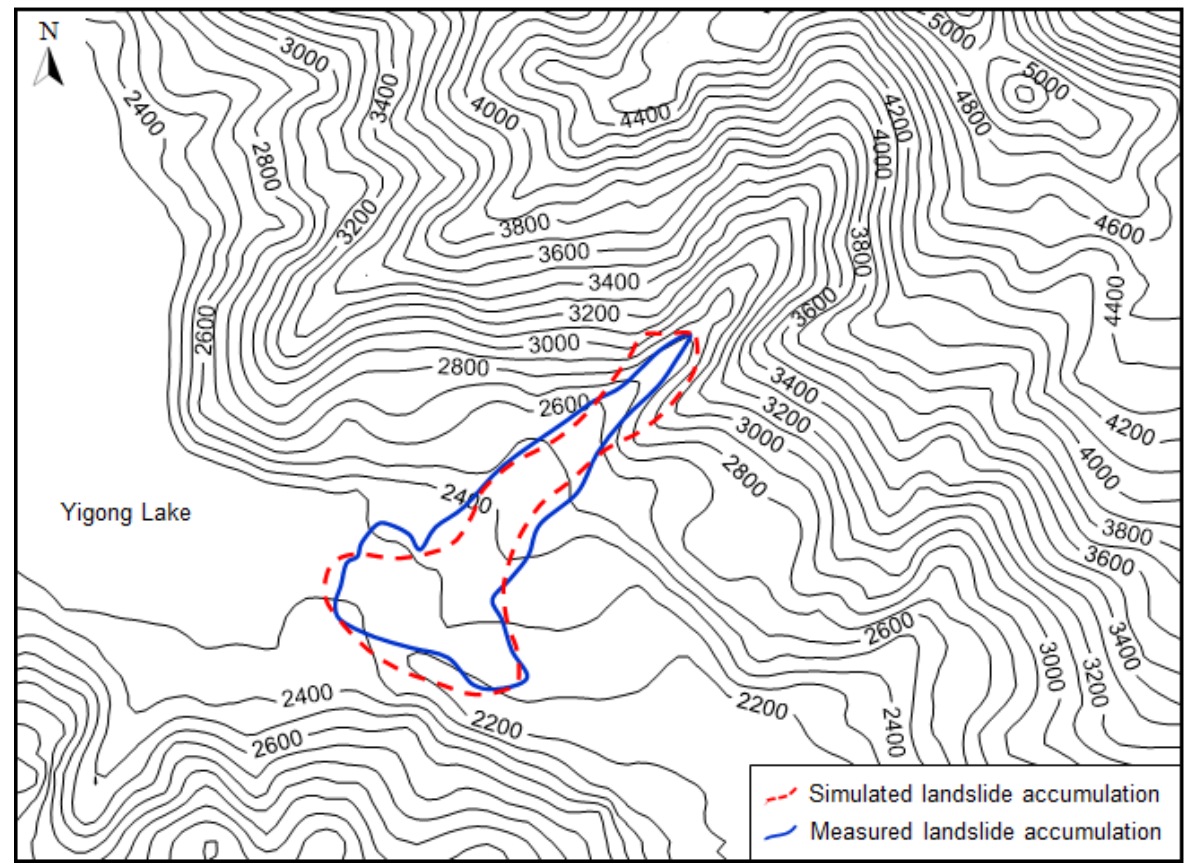

Figure 16: Comparison of the simulated and measured deposition zone of the Yigong landslide. 


\section{Conclusions}

280 Rapid landslides always lead to property loss and human death all over the word. This work investigates the kinetic features of the rapid Yigong landslide on the Tibetan Plateau, China. On the basis of the SPH method, 2D and 3D numerical simulations are conducted to reproduce the motion process of the Yigong landslide. Based on the numerical results and combined with field investigation data and remote-sensing images, the kinetic characteristics of the landslide are analysed. Some conclusions can be obtained as below.

285 In the early stage, landslide body slides down along the deep slope in the source area. It experiences an acceleration and reaches its peak velocity (about $100 \mathrm{~m} / \mathrm{s}$ ). In this stage, most of the potential energy of the landslide body is converted into the kinetic energy. During the landslide propagation in the Zhamunong gully, the kinetic energy continuously dissipates due to the friction and the collision. The velocity gradually slows down in this stage. After rushing out of the Zhamunong gully, the landslide mass crashes into a mountain on the opposite bank of Yigong river and then blocks the river channel. The

290 velocity evolution of the landslide is obtained based on the numerical results, and the final landslide accumulation is predicted, which basically fits the measured data in field.

Although, the SPH model presented in this work can reproduce the motion process and analyse the kinetic characteristics of the Yigong landslide, there are still some problems need to be solved. For example, the bed material entrainment during the landslide propagation has some effect on the landslide volume and its kinetic characteristics, but it is not considered in this 295 work. On the other hand, the disintegration and fragmentation of the rock blocks is not considered in the presented SPH model, which may lead to some error during the simulation of landslide propagation. Besides, high performance parallel computing technology is quite necessary to improve the calculation efficiency in 3D modelling.

\section{Acknowledgments}

The presented work was supported by the Program for Professor of Special Appointment (Eastern Scholar) at Shanghai 300 Institutions of Higher Learning, National Natural Science Foundation of China (grant no. 41807248, and grant no. 41530639).

\section{References}

Bernander, S., Kullingsjo, A., Gylland, A.S., Bengtsson, P.E., Knutsson, S., Pusch, R., Olofsson, J., Elfgren, L.: Downhill progressive landslides in long natural slopes: triggering agents and landslide phases modeled with a finite difference method, Canadian Geotechnical Journal, 53(10), 1565-1582, doi: 10.1139/cgj-2015-0651, 2016. 
Chen, X.Y., Zhang, L.L., Chen, L.H., Li, X., Liu, D.S.: Slope stability analysis based on the Coupled Eulerian-Lagrangian finite element method, Bulletin of Engineering Geology and the Environment, 78(6), 4451-4463, doi: 10.1007/s10064-0181413-4, 2019.

Cuomo, S., Pastor, M., Capobianco, V., Cascini, L.: Modelling the space-time evolution of bed entrainment for flow-like landslides, Engineering Geology, 212: 10-20, doi: 10.1016/j.enggeo.2016.07.011, 2016.

Ding, M., Cai, C., Qin, H.: Accumulation landslide stability analysis based on FLAC numerical simulation. Disaster Advances, 5 (4), 1783-1790, 2012.

Dai, Z.L., Huang, Y., Cheng, H.L., Xu, Q.: 3D numerical modeling using smoothed particle hydrodynamics of flow-like landslide propagation triggered by the 2008 Wenchuan earthquake. Engineering Geology, 180, 21-33, doi: 315 10.1016/j.enggeo.2014.03.018, 2014.

Dai, Z.L., Huang, Y., Cheng, H.L., Xu, Q.: SPH model for fluid-structure interaction and its application to debris flow impact estimation, Landslides, 14, 3, 917-928, doi: 10.1007/s10346-016-0777-4, 2017.

Dai, Z.L., Huang, Y., Xu, Q.: A hydraulic soil erosion model based on a weakly compressible smoothed particle hydrodynamics method, Bulletin of Engineering Geology and the Environment, 78(8), 5853-5864, doi: 10.1007/s10064019-01489-z, 2019.

Dai, Z.L., Wang, F.W., Cheng, Q.G., Wang, Y.F., Yang, H.F., Lin, Q.W., Yan, K.M., Liu, F.C., Li, K.: A giant historical landslide on the eastern margin of the Tibetan Plateau, Bulletin of Engineering Geology and the Environment, 78, 20552068, doi: 10.1007/s10064-017-1226-x, 2019a.

Fan, X., Xu, Q., Scaringi, G., Dai, L.: Failure mechanism and kinematics of the deadly June 24th 2017 Xinmo landslide,

Maoxian, Sichuan, China, Landslides, 14(6), 2129-2146, doi: 10.1007/s10346-017-0907-7, 2017.

Gingold, R.A., Monaghan, J.J.: Smoothed particle hydrodynamics: theory and application to non-spherial stars, Monthly Notices of the Royal Astronomical Society, 181, 375-389, DOI: 10.1093/mnras/181.3.375, 1977.

Hu, M.J., Pan, H.L., Zhu, C.Q. Wang F.W.: High-speed ring shear tests to study the motion and acceleration processes of the Yigong landslide, Journal of Mountain Science, 12(6), 1534-1541, doi: 10.1007/s11629-014-3059-4, 2015.

Huang, R.Q.: Large-scale landslides and their sliding mechanisms in China since the 20th century, Chinese Journal of Rock Mechanics and Engineering, 26(3), 433-454, 2007. (in Chinese with English abstract)

Huang, Y., Cheng, H.: A simplified analytical model for run-out prediction of flow slides in municipal solid waste landfills, Landslides, 14:99-107, doi: 10.1007/s10346-016-0688-4, 2017.

Hungr, O.: A model for the runout analysis of rapid flow slides, debris flows, and avalanches. Canadian Geotechnical Journal, 32(4), 610-623, doi: 10.1139/t95-063, 1995.

Hunter, G., Fell, R.: Travel distance angle for "rapid" landslides in constructed and natural soil slopes, Canadian Geotechnical Journal, 40(6), 1123-1141, doi: 10.1139/T03-061, 2003.

Jamalabadi, M.Y.A.: Frequency analysis and control of sloshing coupled by elastic walls and foundation with smoothed particle hydrodynamics method, Journal of Sound and Vibration, 476, 115310, doi: 10.1016/j.jsv.2020.115310, 2020. 
340 Karantanellis, E., Marinos, V., Vassilakis, E., Christaras, B.: Object-based analysis using Unmanned Aerial Vehicles (UAVs) for site-specific landslide assessment, Remote Sensing, 12(11), 1711, doi: 10.3390/rs12111711, 2020.

Lee, H.Y., Chung, S.L., Wang, J.R., Wen, D.J., Lo, C.H., Yang, T.F., Zhang, Y., Xie, Y., Lee, T.Y., Wu, G., Ji, J.: Miocene Jiali faulting and its implications for Tibetan tectonic evolution, Earth Planet. Sci. Lett. 205, 185-194, doi: 10.1016/S0012821X(02)01040-3, 2003.

345 Liu, M.B., Liu, G.R.: Smoothed particle hydrodynamics (SPH): an overview and recent developments, Archives of Computational Methods in Engineering, 17(1), 25-76, doi: 10.1007/s11831-010-9040-7, 2010.

Liu, Z.Y., Su, L.J., Zhang, C., Iqbal, J., Hu, B.L., Dong, Z.B.: Investigation of the dynamic process of the Xinmo landslide using the discrete element method, Computers and Geotechnics, 123, 103561, doi: 10.1016/j.compgeo.2020.103561, 2020. Ma, C., Iijima, K., Oka, M.: Nonlinear waves in a floating thin elastic plate, predicted by a coupled SPH and FEM simulation and by an analytical solution, Ocean Engineering, 204, 107243, doi: 10.1016/j.oceaneng.2020.107243, 2020.

Maihemuti, B., Wang, E.Z., Hudan, T., Xu, Q.J.: Numerical Simulation Analysis of Reservoir Bank Fractured Rock-Slope Deformation and Failure Processes, International Journal of Geomechanics, 16(2), 04015058, doi: 10.1061/(ASCE)GM.1943-5622.0000533, 2016.

Monaghan, J.J., Gingold, R.A.: Shock simulation by the particle method SPH. Journal of Computational Physics, 52, 374-

355 389, doi: 10.1016/0021-9991(83)90036-0, 1983.

Pastors, M., Blanc, T., Drempetic, V., Dutto, P., Stickle, M.M., Yague, A.: Modelling of Landslides: An SPH Approach, Computer Modeling in Engineering \& Sciences, 109(2): 183-220, 2015.

Peng, X.Y., Yu, P.C., Chen, G.Q., Xia, M.Y., Zhang, Y.B.: CPU-accelerated explicit discontinuous deformation analysis and its application to landslide analysis, Applied Mathematical Modelling, 77: 216-234, doi: 10.1016/j.apm.2019.07.028, 2020.

360 Pirulli, M.: Morphology and substrate control on the dynamics of flowlike landslides, Journal of Geotechnical and Geoenvironmental Engineering, 136, 376-388, doi: 10.1061/(ASCE)GT.1943-5606.0000221, 2010.

Price, D.J., Laibe, G.: A solution to the overdamping problem when simulating dust-gas mixtures with smoothed particle hydrodynamics, Monthly Notices of the Royal Astronomical Society, 495(4), 3929-3934, doi: 10.1093/mnras/staa1366, 2020.

365 Pu, X.W., Wang, L.M., Wang, P., Chai, S.F.: Study of shaking table test of seismic subsidence loess landslides induced by the coupling effect of earthquakes and rainfall, Natural Hazards, doi.org/10.1007/s11069-020-04019-3, 2020.

Qiu, H.J., Cui, P., Hu, S., Regmi, A.D., Wang, X.G., Yang, D.D.: Developing empirical relationships to predict loess slide travel distances: a case study on the Loess Plateau in China, Bulletin of Engineering Geology and the Environment, 77(4), 1299-1309, doi: 10.1007/s10064-018-1328-0, 2018.

370 Shang, Y.J., Yue, Z.Q., Yang, Z.F., Wang, Y.C., Liu, D.A.: Addressing severe slope failure hazards along Sichuan-Tibet highway in southwestern China, Episodes-Newsmagazine of the International Union of Geological Sciences, 26(2), 94-104, doi:10.1007/s00254-003-0776-3, 2003a. 
Shang, Y.J., Yang, Z.F., Li, L.H., Liu, D., Liao, Q.L., Wang, Y.C.: A super-large landslide in Tibet in 2000: background, occurrence, disaster, and origin, Geomorphology 54, 225-243, doi: 10.1016/S0169-555X(02)00358-6, 2003 b.

Su, X., Wei, W.H., Ye, W.L., Meng, X.M., Wu, W.J.: Predicting landslide sliding distance based on energy dissipation and mass point kinematics, Natural Hazards, 96(3), 1367-1385, doi: 10.1007/s11069-019-03618-z, 2019.

Tang, M.G., Li, S.L., Xu, Q., Gong, Z.F., Zhu, Q., Wei, Y.: Study of deformation characteristics of reservoir landslide based on centrifugal model test, Rock and Soil Mechanics, 41(3), 755-764, doi: 10.16285/j.rsm.2019.0214, 2020.

Tang, S.B., Huang, R.Q., Tang, C.A., Liang, Z.Z., Heap, M.J.: The failure processes analysis of rock slope using numerical modelling techniques, Engineering Failure Analysis, 79: 999-1016, doi: 10.1016/j.engfailanal.2017.06.029, 2017.

Wang, H.L., Liu, S.Q., Xu, W.Y., Yan, L., Qu, X., Xie, W.C.: Numerical investigation on the sliding process and deposit feature of an earthquake-induced landslide: a case study, Landslides, doi: 10.1007/s10346-020-01446-y, doi: 10.1007/s10346-020-01446-y, 2020.

Wang, Y.F., Dong J.J., Cheng Q.G.: Velocity-dependent frictional weakening of large rock avalanche basal facies: Implications for rock avalanche hypermobility? Journal of Geophysical Research: Solid Earth, 122, 1648-1676, doi: 10.1002/2016JB013624, 2017.

Wei, J.B., Zhao, Z., Xu, C., Wen, Q.: Numerical investigation of landslide kinetics for the recent Mabian landslide (Sichuan, China), Landslides, 16, 2287-2298, doi: 10.1007/s10346-019-01237-0, 2019.

Xie, J.R., Uchimura, T., Wang, G.H., Selvarajah, H., Maqsood, Z., Shen, Q., Mei, G.X., Qiao, S.F.: Predicting the sliding behavior of rotational landslides based on the tilting measurement of the slope surface, Engineering Geology, 269, 105554, doi: 10.1016/j.enggeo.2020.105554, 2020.

Xiong, X., Shi, Z.M., Guan, S.G., Zhang, F.: Failure mechanism of unsaturated landslide dam under seepage loading-Model tests and corresponding numerical simulations, Soils and Foundations, 58(5), 1133-1152, doi: 10.1016/j.sandf.2018.05.012, 2018.

395 Xu, Q., Shang, Y., van Asch, T., Wang, S., Zhang, Z., Dong, X.: Observations from the large, rapid Yigong rock slidedebris avalanche, southeast Tibet, Canadian Geotechnical Journal, 49,589-606, doi: 10.1139/T2012-021, 2012.

Yin, Y.P.: Characteristics of Bomi-Yigong huge high speed landslide in Tibet and the research on disaster prevention, Hydrogeology and Engineering Geology, 4, 8-11, 2000. (in Chinese with English abstract)

Yu, M., Huang, Y., Deng, W.B., Cheng, H.L.: Forecasting landslide mobility using an SPH model and ring shear strength 400 tests: a case study. Natural Hazards and Earth System Sciences, 18(12): 3343-3353, doi: 10.5194/nhess-18-3343-2018, 2018.

Zhang, W.J., Xiao, D.Q.: Numerical analysis of the effect of strength parameters on the large-deformation flow process of earthquake-induced landslides, Engineering Geology, 260, 105239, doi: 10.1016/j.enggeo.2019.105239, 2019.

Zhang, W.J., Ji, J., Gao, Y.F., Li, X.Y., Zhang, C.S.: Spatial variability effect of internal friction angle on the post-failure 405 behavior of landslides using a random and non-Newtonian fluid based SPH method, Geoscience Frontiers, 11(4): 1107-1121, doi: 10.1016/j.gsf.2020.02.003, 2020. 
https://doi.org/10.5194/nhess-2020-289

Preprint. Discussion started: 27 October 2020

(c) Author(s) 2020. CC BY 4.0 License.

(c) (1)

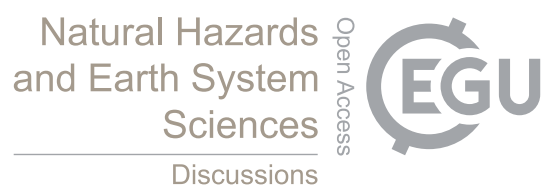

Zhou, C., Hu, X.L., Zheng, W.B., Xu, C., Wang, Q.: Displacement characteristic of landslides reinforced with flexible piles: field and physical model test, Journal of Mountain Science, 17(4), 787-800, doi: 10.1007/s11629-019-5743-x, 2020.

Zhou, J.W., Cui, P., Hao, M.H.: Comprehensive analyses of the initiation and entrainment processes of the 2000 Yigong 410 catastrophic landslide in Tibet, China, Landslides, 13: 39-54, doi: 10.1007/s10346-014-0553-2, 2016

Zhu, C.Q., Huang, Y., Sun, J.: Solid-like and liquid-like granular flows on inclined surfaces under vibration - Implications for earthquake-induced landslides, Computers and Geotechnics, 123, 103598, doi: 10.1016/j.compgeo.2020.103598, 2020.

Zhu, G.X., Zou, L.: An integrated smoothed particle hydrodynamics model for complex interfacial flows with large density ratios, International Journal for Numerical Methods in Fluids, 92(8): 950-975, doi: 10.1002/fld.4813, 2020. 